\title{
Use of cosmic-ray neutron sensors for soil moisture monitoring in forests
}

\author{
Ingo Heidbüchel, Andreas Güntner, and Theresa Blume \\ GFZ German Research Centre for Geosciences, Potsdam, Germany \\ Correspondence to: Ingo Heidbüchel (ingo.heidbuechel@gfz-potsdam.de)
}

Received: 23 August 2015 - Published in Hydrol. Earth Syst. Sci. Discuss.: 25 September 2015

Revised: 7 March 2016 - Accepted: 16 March 2016 - Published: 30 March 2016

\begin{abstract}
Measuring soil moisture with cosmic-ray neutrons is a promising technique for intermediate spatial scales. To convert neutron counts to average volumetric soil water content a simple calibration function can be used (the $N_{0^{-}}$ calibration of Desilets et al., 2010). The calibration is based on soil water content derived directly from soil samples taken within the footprint of the sensor. We installed a cosmic-ray neutron sensor (CRS) in a mixed forest in the lowlands of north-eastern Germany and calibrated it 10 times throughout one calendar year. Each calibration with the $N_{0}$-calibration function resulted in a different CRS soil moisture time series, with deviations of up to $0.1 \mathrm{~m}^{3} \mathrm{~m}^{-3}$ (24\% of the total range) for individual values of soil water content. Also, many of the calibration efforts resulted in time series that could not be matched with independent in situ measurements of soil water content. We therefore suggest a modified calibration function with a different shape that can vary from one location to another. A two-point calibration was found to effectively define the shape of the modified calibration function if the calibration points were taken during both dry and wet conditions spanning at least half of the total range of soil moisture. The best results were obtained when the soil samples used for calibration were linearly weighted as a function of depth in the soil profile and nonlinearly weighted as a function of distance from the CRS, and when the depth-specific amount of soil organic matter and lattice water content was explicitly considered. The annual cycle of tree foliation was found to be a negligible factor for calibration because the variable hydrogen mass in the leaves was small compared to the hydrogen mass changes by soil moisture variations. As a final point, we provide a calibration guide for a CRS in forested environments.
\end{abstract}

\section{Introduction}

Determining average soil moisture content over larger areas is difficult, mainly for two reasons. First, soil moisture can be highly variable even at small spatial scales, especially under intermediate wetness conditions (e.g., Western et al., 2004). Second, most common in situ measurement techniques only yield point measurements. To obtain a valid estimate of area-average soil moisture one needs to collect data from numerous locations within a given area. This can be time-consuming and expensive. More recently, remote sensing of soil moisture at larger scales has become a research focus (e.g., see Ochsner et al. (2013) for a recent review); however, the measurement depth of many of these methods is still limited to the upper $5 \mathrm{~cm}$ of the soil. Also, both spatial and temporal resolution is rather coarse. A technique that intends to bridge the scale gap between point measurements of soil moisture and remote sensing is the use of cosmic-ray neutrons as indicators of soil moisture. A detailed description of the cosmic-ray neutron sensor (CRS) can be found in Zreda et al. (2008, 2012); here we will only describe the basic measurement principle. Cosmic-ray neutrons on Earth are formed when high-energy protons derived from galactic sources (such as supernovae) enter the Earth's atmosphere. Once in the atmosphere, the protons interact with atomic nuclei (mainly nitrogen and oxygen) producing cascades of secondary neutrons (also called high-energy neutrons) that travel towards the Earth's surface and into the soils. When secondary neutrons interact with air or soil nuclei they trigger the release (evaporation) of fast neutrons. The number of fast neutrons above the soil surface depends strongly on the number of hydrogen atoms in the surroundings because hydrogen atoms have a very high capacity to moderate fast cosmic-ray neutrons (that means to slow them down and turn them into 
thermal neutrons with even less energy - effectively removing the fast neutrons from the system). The number of hydrogen atoms increases with increasing soil water content and hence soils with high water contents re-emit fewer fast neutrons than soils with low water content. That leads to fewer fast neutrons being detected aboveground by the CRS, which is generally installed $1-2 \mathrm{~m}$ above the soil surface.

Previously, Hendrick and Edge (1966) reported that the intensity of fast (low-energy) neutrons $(\sim 1 \mathrm{keV})$ detected above the ground depended on the hydrogen content of the soil, and Kodama et al. (1985) found an inverse correlation of neutron intensity and soil moisture content with a neutron sensor buried in the soil. In 2008, Zreda et al. (2008) introduced a method to measure average soil water content over a larger area $(\sim 30 \mathrm{ha})$ with a CRS. The footprint of a CRS, i.e., the area around the sensor where $86 \%$ of detected neutrons originate from, covers a circle with an approximate radius of $300 \mathrm{~m}$ (Desilets and Zreda, 2013). However, the radius can decrease with increasing air density and humidity, with increasing vegetation density and with increasing soil moisture to about $100 \mathrm{~m}$ (Köhli et al., 2015). The effective measurement depth of a CRS, i.e., the soil depth where $86 \%$ of detected neutrons originate from, varies between 10 and $70 \mathrm{~cm}$ below surface (Zreda et al., 2008), depending on soil type, water content and distance from the sensor (Köhli et al., 2015). To account for the contributions of neutrons from different soil depths, various depth-weighting approaches have been proposed, some of them assuming a linear decrease of weights with depth (Franz et al., 2012a), others assuming a nonlinear decrease with depth (Köhli et al., 2015).

The original measurement method uses a relationship between neutron flux and volumetric soil water content with the shape of the relationship being known from neutron transport simulations. For this relationship, Desilets et al. (2010) presented an equation with three constant shape parameters $\left(a_{0}\right.$, $\left.a_{1}, a_{2}\right)$ and one calibration parameter $\left(N_{0}\right)$, which has to be calibrated with soil moisture values determined by the gravimetric method from field soil samples. The influence of soil lattice water and soil organic matter on the signal was investigated by Zreda et al. (2012). They found that both lattice water and soil organic matter contain fixed amounts of hydrogen that further attenuate the neutron signal and need to be taken into account. Lattice water and soil organic matter corrections to the original relationship by Desilets et al. (2010) are provided for example in Lv et al. (2014).

Other external factors influencing the neutron count that need to be corrected for are (a) atmospheric pressure (Bachelet et al., 1965), (b) incoming neutron flux (see e.g., Zreda et al., 2012, Bogena et al., 2013) and (c) specific humidity (Rosolem et al., 2013). More recently, the effects of biomass on the neutron signal have been discussed. Bogena et al. (2013) noted that aboveground biomass reduced the neutron count rate and thus decreased the sensitivity of the sensor. To counter this loss of sensitivity they recommended a $24 \mathrm{~h}$ integration time for their forested catchment as a com- promise between decreased uncertainty and decreased time resolution. Hawdon et al. (2014) and Baatz et al. (2015) compared neutron counts for locations with different amounts of biomass. Hawdon et al. (2014) reported that the variation in biomass could explain $80 \%$ of the variation in neutron counts when assuming a nonlinear relationship between biomass and neutron counts; Baatz et al. (2015) explained $87 \%$ of the variation proposing a linear relationship between the two variables. Baroni and Oswald (2015) suggested that the influence of aboveground biomass between the sensor and the ground, which decreases the effective measurement depth of the CRS, can be incorporated into the weighting approach of Franz et al. (2012a). This is especially important in locations where frequent large biomass changes occur, for example in agricultural fields. Coopersmith et al. (2014) found that soil moisture in a corn crop is often overestimated when the leaf area index (LAI) is relatively high while it is underestimated when LAI is relatively low - circumstances which could cause differences in the calibration and resulting soil moisture measurements. The influence of the litter layer in forested environments was investigated by Bogena et al. (2013). Water content in the litter layer changes rapidly and adds additional temporal variability to the CRS time series complicating the extraction of the soil moisture signal. Therefore, Bogena et al. (2013) recommended considering the water dynamics in the litter layer explicitly in the calibration approach. Franz et al. (2013) introduced a new approach (the universal calibration function) that takes into account all sources of hydrogen thereby requiring estimates of lattice water, soil organic carbon and vegetation biomass, as well as a regression factor that can be derived from calibration or may directly be retrieved from neutron count measurements over a large water body $(500 \mathrm{~m}$ on all sides and deeper than $1 \mathrm{~m})$.

Since the launch of the cosmic-ray neutron method many changes and corrections have been brought forward that altered the way the method is applied. These changes and corrections can be divided into two groups. On the one hand, there are corrections that are applied to the raw neutron count in order to remove the influence of other variables (such as air pressure and humidity variations or fluctuations in incoming neutron counts). On the other hand, changes have been made to the way we average the soil moisture measurements during the calibration campaigns in order to get a representative soil moisture value that corresponds to what the sensor actually "sees" at the time of calibration (changing effective measurement depth, changing footprint diameter, inclusion of lattice water and soil organic matter water equivalent). All this has led to improvements in the method's accuracy for many environments. Most of these studies were performed in medium- to high-count environments with neutron count rates above 1000 counts per hour, in generally dry environments, at higher elevations and with little vegetation. Only a few studies were performed in low-count environments with count rates below 1000 counts per hour (e.g., Rivera 


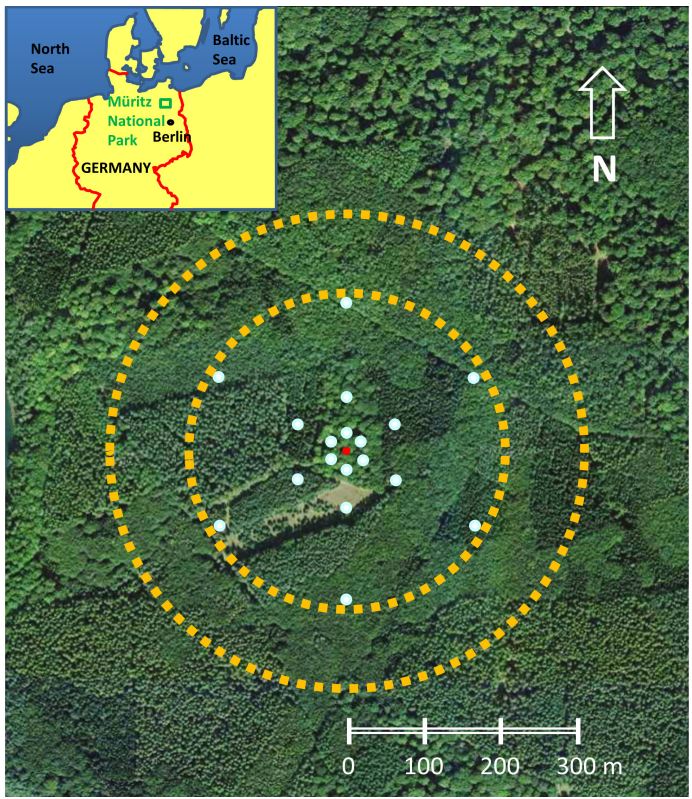

Figure 1. Soil sampling locations for calibration (white dots) and forest vegetation around the CRS (red dot in the center). The TDT soil moisture sensors are located in close vicinity to the sampling locations. The larger yellow circle approximates the footprint of the CRS as it was assumed when sampling took place (diameter approximately $300 \mathrm{~m}$ ). The smaller yellow circle approximates the footprint of the CRS according to newer modeling results by Köhli et al. (2015) (diameter approximately $200 \mathrm{~m}$ ). Inset: field site location in Müritz National Park in north-eastern Germany.

Villareyes et al., 2011; Bogena et al., 2013). In the present study, we evaluated whether the CRS also provides reliable and consistent soil moisture measurements in a low-count environment, i.e., in a temperate mixed forest close to sea level. We tested several weighting approaches to convert gravimetrically determined soil water content of the top $30 \mathrm{~cm}$ into an average soil water content that can be used for the calibration of the CRS. Additionally, we analyzed whether the annual forest cycle of foliation and defoliation is important to consider for instrument calibration. We furthermore compiled a best-practice for the calibration of a CRS in forested, low-count environments, which is provided in Appendix A.

\section{Field site and instrumentation}

The CRS (CRS-1000 by Hydroinnova) was installed in late 2013 in the Müritz National Park in north-eastern Germany $\left(53^{\circ} 19^{\prime} 49.0^{\prime \prime} \mathrm{N}, 13^{\circ} 11^{\prime} 56.5^{\prime \prime} \mathrm{E}\right)$ at an elevation of about $84 \mathrm{~m}$ a.m.s.l. (Fig. 1, inset). Precipitation, temperature and relative humidity data were provided by the climate station Serrahn (1.6 km to the north). Average annual air temperature at the site is $8{ }^{\circ} \mathrm{C}$ with a maximum in July $\left(17.2^{\circ} \mathrm{C}\right)$ and a minimum in January $\left(-0.9^{\circ} \mathrm{C}\right)$. Average annual precipitation is $580 \mathrm{~mm}$ with a maximum in June $(65 \mathrm{~mm})$ and
Table 1. Fractions of different tree stands in percent within the footprint of the CRS. The total represents a distance-weighted average with an exponential decay towards more distant areas (approximating the exponential distance weighting from Zreda et al., 2008).

\begin{tabular}{lcccc}
\hline & $\begin{array}{c}\text { Radius } \\
0-50 \mathrm{~m}\end{array}$ & $\begin{array}{c}\text { Radius } \\
50-150 \mathrm{~m}\end{array}$ & $\begin{array}{c}\text { Radius } \\
150-300 \mathrm{~m}\end{array}$ & Total \\
\hline Beech & 85.2 & 32.8 & 48.7 & 55.5 \\
Pine & 3.0 & 26.3 & 17.6 & 15.6 \\
Spruce & 5.8 & 20.9 & 11.1 & 12.6 \\
Oak & 0.0 & 10.3 & 12.5 & 7.6 \\
Open (grass) & 6.0 & 9.7 & 3.9 & 6.5 \\
Larch & 0.0 & 0.0 & 5.5 & 1.8 \\
Birch & 0.0 & 0.0 & 0.7 & 0.2 \\
\hline
\end{tabular}

a minimum in February $(28 \mathrm{~mm})$. This makes for a maritime temperate climate $(\mathrm{Cfb})$ in the Köppen climate classification. The sensor is located in a sandy outwash plain, a relic from the last glaciation, which causes the soil texture to be homogeneous with sand fractions of about $95 \%$ throughout the entire profile. Data from a nearby well show that the groundwater level at the site is almost $20 \mathrm{~m}$ below the terrain surface. The vegetation within the sensor footprint consists of both deciduous and coniferous trees. Immediately surrounding the sensor is a mature beech forest (Fagus sylvatica L., older than 100 years), also within the footprint (but farther away) with a distance of at least $40 \mathrm{~m}$ from the sensor there is young pine (Pinus sylvestris L.), oak (Quercus robur L.) and spruce (Picea abies (L.) H. Karst.) forest (all younger than 50 years) as well as a small strip of open grassland (see Fig. 1 and also Fig. 3 for a map of the forest stands and Table 1 for fractions of the different tree stands within the footprint). Depending on the tree species, the mineral soil is covered by an organic soil layer and a litter layer of variable depth and water holding capacity.

For validation of the CRS soil water content measurements, in May of 2014 we installed 18 soil moisture sensors (TMS dataloggers from TOMST) close to the soil sampling/calibration locations. They are based on the principle of time domain transmission (TDT) and each sensor comes with its own logger and power supply (more information under: http://www.tomst.cz/tms/TMS-3.html). These sensors were installed vertically from the terrain surface into the soil so that they continuously measure soil water content averaged over the top $16 \mathrm{~cm}$ of the soil. In order to calibrate the sensors, we used the gravimetric soil moisture data we collected from the upper $15 \mathrm{~cm}$ during the last five calibration campaigns, which were carried out within the measurement period of the sensors (June-November 2014). The volumetric water content within the upper $15 \mathrm{~cm}$ of the CRS footprint was calculated as the mean of all 18 TDT sensors. 


\section{Methods}

\subsection{Calibration}

We conducted a total of 10 calibration campaigns throughout one calendar year (2014). The first one (WI) took place in February during winterly conditions with very wet soils. The next four calibrations (S1-4) followed in spring (April-May) and covered the entire period of tree foliation. The sixth calibration (SU) was done under very dry conditions in July and the last four calibrations (F1-4) in fall (October-November) covering the trees' defoliation. For all the calibration campaigns, we followed the recommended sampling pattern for the calibration of CRS, which was developed by Zreda et al. (2012) and slightly modified and detailed in Franz et al. (2012b). The sampling pattern prescribes three concentric circles around the CRS with radii of 25,75 and $200 \mathrm{~m}$ (Fig. 1). The three circles are intersected by six straight lines that point from the sensor towards north $\left(0^{\circ}\right)$, northeast $\left(60^{\circ}\right)$, south-east $\left(120^{\circ}\right)$, south $\left(180^{\circ}\right)$, south-west $\left(240^{\circ}\right)$ and north-west $\left(300^{\circ}\right)$. Samples are taken in the vicinity of all intersections - the samples do not have to be taken at the exact spot of the intersection. This sampling pattern ensures that each sample has equal weight towards the spatial mean of soil moisture that is detected by the CRS, assuming that the sensitivity of the CRS decreases exponentially with distance. We used a split-tube sampler to extract $30 \mathrm{~cm}$ soil cores at 18 locations within the footprint of the sensor afterwards dividing each soil core into six $5 \mathrm{~cm}$ thick soil samples. For each of the 10 calibrations this left us with 108 soil samples, which were then transferred in sealed plastic bags to the laboratory where they were immediately weighed, then oven-dried at $105^{\circ} \mathrm{C}$ for $24 \mathrm{~h}$ and then weighed again to determine their volumetric water content and bulk density. Afterwards, lattice water, soil organic matter content and root biomass were determined for six depth-representative soil samples. To this end the 108 samples (taken from the last calibration campaign in November) were grouped by sampling depth. We extracted $2 \mathrm{~g}$ from each of the 18 samples per sampling depth and combined them to create one bulk sample per depth. Then, the already oven-dried samples were weighed and put in the oven for another $24 \mathrm{~h}$ at a temperature of $400^{\circ} \mathrm{C}$. The procedure is called "loss on ignition" since the organic matter is burned off during the process (Ball, 1964; Davies, 1974). This removed most of the soil organic matter and root biomass from the samples. After weighing the samples (to compute the fraction of combined soil organic matter and root biomass) they were again placed in the oven for $24 \mathrm{~h}$, this time at a temperature of about $1000^{\circ} \mathrm{C}$. After that, the lattice water was also removed from the samples. A final weighing yielded the fraction of lattice water per soil depth. In order to make soil organic matter and root biomass comparable to the influence of pure water we converted them into equivalents of water by multiplying their weight by 0.556 , which is the ratio of 5 times the molecular weight of water to the molecular weight of cellulose (taking into account that cellulose $\left(\mathrm{C}_{6} \mathrm{H}_{10} \mathrm{O}_{5}\right)$ contains 10 hydrogen atoms per molecule while water $\left(\mathrm{H}_{2} \mathrm{O}\right)$ only contains 2) (Hawdon et al., 2014).

The neutron counts from the sensor were smoothed with a $12 \mathrm{~h}$ moving window to reduce measurement noise (see Bogena et al., 2013). The next step was to correct the neutron counts for variations in (a) pressure, (b) incoming neutron flux and (c) water vapor in the air. This was done by applying the following corrections:

a. Pressure correction,

$N_{\mathrm{p}}=N_{\mathrm{raw}} \cdot e^{\left(\frac{x-x_{0}}{L}\right)}$,

with $N_{\mathrm{p}}$ being the pressure corrected neutron counts (counts $\mathrm{h}^{-1}$ ), $N_{\text {raw }}$ the raw neutron counts (counts $\mathrm{h}^{-1}$ ), $x$ the atmospheric shielding depth $\left(\mathrm{g} \mathrm{cm}^{-2}\right)$ for every time step (derived from atmospheric pressure measured directly inside the CRS case), $x_{0}$ the average atmospheric shielding depth $\left(\mathrm{g} \mathrm{cm}^{-2}\right)$ for the entire measurement period and $L$ the effective nucleon attenuation length for high-energy neutrons (for our site we assumed a value of $135.9 \mathrm{~g} \mathrm{~cm}^{-2}$, which is equivalent to $133.3 \mathrm{hPa}$ ) (Desilets and Zreda, 2003). To convert atmospheric pressure $(\mathrm{hPa})$ into shielding depth $\left(\mathrm{g} \mathrm{cm}^{-2}\right)$ the atmospheric pressure has to be multiplied by $1.0194 \mathrm{~s}^{2} \mathrm{~m}^{-1}$.

b. Incoming flux correction (Zreda et al., 2012),

$N_{\mathrm{pi}}=N_{\mathrm{p}} \cdot \frac{N_{\mathrm{avg}}}{N_{\mathrm{nm}}}$

with $N_{\text {pi }}$ being the sensor neutron count rate corrected for changes in atmospheric pressure and incoming neutrons (counts h ${ }^{-1}$ ), $N_{\text {avg }}$ the average count rate of incoming neutrons (counts $\mathrm{h}^{-1}$ ) over the entire measurement period and $N_{\mathrm{nm}}$ the neutron count rate of the neutron monitor for each time step (counts $\mathrm{h}^{-1}$ ).

As the time series of the closest neutron monitor, located in Kiel, Germany, contains several data gaps, we selected the continuous time series of the Jungfraujoch, Switzerland, for this study. We scaled this time series by adjusting its mean ( 309 counts $\left.^{-1}\right)$ to the mean of the Kiel time series $\left(327\right.$ counts $\mathrm{h}^{-1}$ ). The resulting time series resembles the Kiel time series very closely (Fig. S1 in the Supplement).

c. Water vapor correction (Rosolem et al., 2013),

$N_{\text {pih }}=N_{\mathrm{pi}} \cdot\left[1+0.0054 \cdot\left(p_{v 0}-p_{v 0}^{\mathrm{ref}}\right)\right]$,

with $N_{\text {pih }}$ being the sensor neutron count corrected for changes in pressure, incoming neutrons and water vapor $\left(\right.$ counts $\left.\mathrm{h}^{-1}\right), p_{v 0}^{\text {ref }}$ the average absolute humidity of 
Table 2. Overview of the four weighting approaches for other than soil moisture effects on the CRS signal.

\begin{tabular}{lcccc}
\hline Approach & 1 SDW & 2 DSW & 3 DDW & 4 DDWnl \\
\hline Consideration of depth- & no & yes & yes & yes \\
specific $W_{\mathrm{L}}$ and SOM $+B_{\mathrm{R}}$ & & no & yes & yes \\
Distance depth weighting & no & no & no & yes \\
Nonlinear depth weighting & no & no
\end{tabular}

the air over the entire measurement period $\left(\mathrm{g} \mathrm{m}^{-3}\right)$ and $p_{v 0}$ the absolute humidity for each time step $\left(\mathrm{g} \mathrm{m}^{-3}\right)$.

The constant 0.0054 has units of $\mathrm{m}^{3} \mathrm{~g}^{-1}$.

Finally, to convert corrected neutron counts $\left(N_{\text {pih }}\right)$ into volumetric soil moisture $(\theta)$, Desilets et al. (2010) introduced an equation with four parameters - three of which $\left(a_{0}=0.0808\right.$, $\left.a_{1}=0.372, a_{2}=0.115\right)$ were determined via neutron transport simulations and a fourth one $\left(N_{0}\right)$ that serves as a calibration parameter accounting for site and sensor-specific variations and representing neutron counts over dry soil at reference conditions during calibration. Calibration has to be performed using the total belowground hydrogen pool including hydrogen contributions from lattice water $\left(W_{\mathrm{L}}\right)$, soil organic matter $(\mathrm{SOM})$ and root biomass $\left(B_{\mathrm{R}}\right)$. Soil water content is then computed by subtracting the other hydrogen pools from the measured neutron-derived signal:

$$
\begin{aligned}
\theta(t) & =\left\{\left[a_{0} \cdot\left(\frac{N_{\mathrm{pih}}(t)}{N_{0}}-a_{1}\right)^{-1}-a_{2}\right] \cdot \rho_{\mathrm{bd}}\right\} \\
& -W_{\mathrm{L}}-\left(\mathrm{SOM}+B_{\mathrm{R}}\right) .
\end{aligned}
$$

The other parameters, $\rho_{\mathrm{bd}}, W_{\mathrm{L}}, \mathrm{SOM}$ and $B_{\mathrm{R}}$, can be measured directly from the calibration soil samples: the bulk density of the soil $\left(\rho_{\mathrm{bd}}\right.$ in $\left.\mathrm{g} \mathrm{cm}^{-3}\right)$, the summed volume fraction of lattice water in the soil grains and tightly bound water $\left(W_{\mathrm{L}}\right.$ in $\mathrm{m}^{3} \mathrm{~m}^{-3}$ ), the combined volume fraction of soil organic matter and root biomass water equivalent $\left(\mathrm{SOM}+B_{\mathrm{R}}\right.$ in $\mathrm{m}^{3} \mathrm{~m}^{-3}$ ). In order to calibrate the sensor, one first has to determine the depth- (and distance-) weighted averages for $\rho_{\mathrm{bd}}, W_{\mathrm{L}}, \mathrm{SOM}+B_{\mathrm{R}}$ and $\theta$ as well as $N_{\text {pih }}$ (averaged over $12 \mathrm{~h}$ ) for the time of calibration. This is necessary because several factors can influence the effective measurement depth $z^{*}$ (which is the depth of the soil layer up to which $86 \%$ of the neutrons that the CRS detects originate from) and the footprint size of the sensor (Fig. 2). Afterwards $N_{0}$ is adjusted iteratively (e.g., with a simple Solver routine in Microsoft Excel) until the right-hand side of the equation equals the left-hand side.

We tested four soil moisture weighting approaches (Table 2), described in detail below, to determine which information is necessary for an accurate calibration.

1. In the first approach (simple depth weighting, SDW) a linear depth-weighting function was used (Franz et al., $2012 \mathrm{~b}$ ), where $\mathrm{wt}(z)$ represents the weight that is ap-

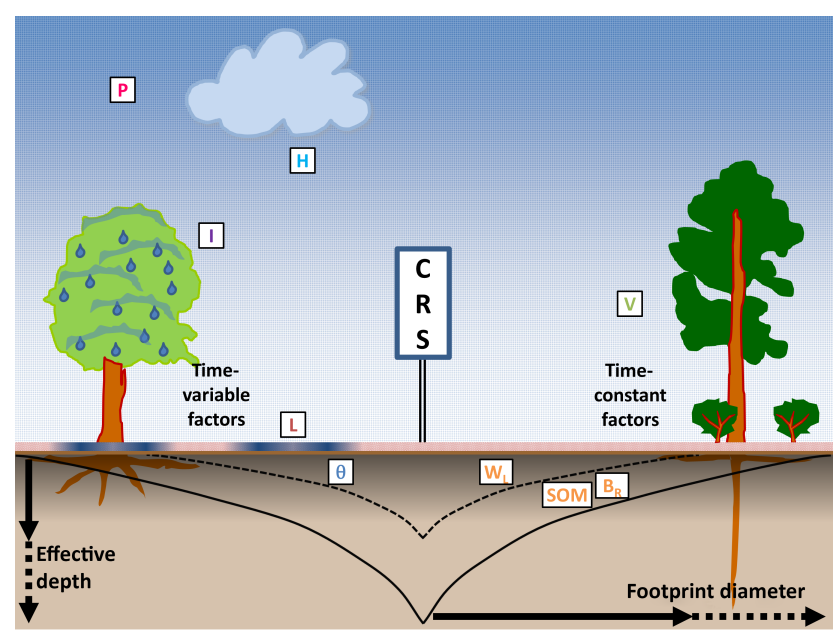

Figure 2. Simplified representation of factors influencing the raw neutron count and the measurement support volume of the CRS in terms of effective measurement depth and footprint. Temporally variable factors are shown on the left: barometric pressure $(P)$, canopy interception $(I)$, air humidity $(H)$ and litter layer interception $(L)$. Temporally constant factors (for our study site) are shown on the right: vegetation above and below the sensor $(V)$, soil organic matter $(\mathrm{SOM})$, root biomass $\left(B_{\mathrm{R}}\right)$ and lattice water $\left(W_{\mathrm{L}}\right)$. All these factors need to be accounted for in order to isolate the soil water content signal $(\theta)$. The time-variable factors require permanent monitoring and dynamic correction, the influence of the constant factors is taken into account during calibration. The combination of time-variable and time-constant factors leads to a reduction of the maximum effective depth and footprint diameter (solid black line) and creates a site-specific temporally variable effective measurement depth and footprint diameter (dashed black line).

plied to the soil moisture measurements from a certain soil depth $z$ :

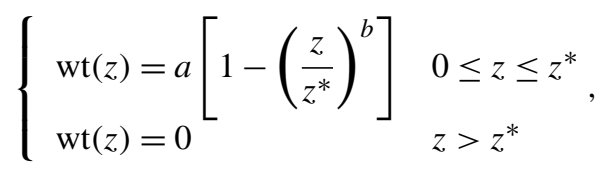

where

$$
\begin{aligned}
& a=\frac{1}{z^{*}}-\frac{z^{* b+1}}{(b+1) z^{* b}}, \\
& z^{*}=\frac{5.8}{H_{\mathrm{p}}+0.0829},
\end{aligned}
$$

and

$H_{\mathrm{p}}=W_{\mathrm{L}}+\mathrm{SOM}+B_{\mathrm{R}}+\theta$.

In these equations $z$ is the soil depth below the surface in centimeters and $z^{*}$ is the effective measurement depth in centimeters, $a$ is a parameter that ensures that 
Table 3. Example of depth weighting (DSW) for an effective measurement depth of $z^{*}=22.1 \mathrm{~cm}, a=0.0903$ and $b=1$. Calibration campaign date 21 November $2014(\mathrm{~F} 4)$. Note the difference in specific weights if only soil water content $\theta$ is $\operatorname{considered}($ wt $(z, \theta))$ or if $W_{\mathrm{L}}$ and $\mathrm{SOM}+B_{\mathrm{R}}$ are also considered $\left(\mathrm{wt}\left(z, H_{\mathrm{p}}\right)\right)$.

\begin{tabular}{lccccc}
\hline $\begin{array}{l}\text { Layer } \\
(\mathrm{cm})\end{array}$ & $\begin{array}{c}\theta \\
\left(\mathrm{m}^{3} \mathrm{~m}^{-3}\right)\end{array}$ & $\begin{array}{c}W_{\mathrm{L}} \\
\left(\mathrm{m}^{3} \mathrm{~m}^{-3}\right)\end{array}$ & $\begin{array}{c}\mathrm{SOM}+B_{\mathrm{R}} \\
\left(\mathrm{m}^{3} \mathrm{~m}^{-3}\right)\end{array}$ & $\begin{array}{c}H_{\mathrm{p}} \\
\left(\mathrm{m}^{3} \mathrm{~m}^{-3}\right)\end{array}$ & $\begin{array}{c}\rho_{\mathrm{bd}} \\
\left(\mathrm{g} \mathrm{cm}^{-3}\right)\end{array}$ \\
\hline $0-5$ & 0.187 & 0.002 & 0.034 & 0.223 & 0.669 \\
$5-10$ & 0.136 & 0.004 & 0.024 & 0.163 & 1.143 \\
$10-15$ & 0.117 & 0.004 & 0.019 & 0.140 & 1.217 \\
$15-20$ & 0.109 & 0.004 & 0.015 & 0.129 & 1.256 \\
$20-25$ & 0.106 & 0.005 & 0.013 & 0.124 & 1.359 \\
$25-30$ & 0.100 & 0.005 & 0.012 & 0.118 & 1.431 \\
\hline \multicolumn{5}{c}{$z+5$} \\
$z(\mathrm{~cm})$ & $\mathrm{wt}(z, \theta)$ & $\int_{z} \mathrm{wt}(z, \theta)$ & $\mathrm{wt}\left(z, H_{\mathrm{p}}\right)$ & $\int_{z}+5 \mathrm{wt}\left(z, H_{\mathrm{p}}\right)$ \\
\hline 0 & 0.079 & 0.356 & 0.090 & 0.401 & \\
5 & 0.063 & 0.278 & 0.070 & 0.299 & \\
10 & 0.048 & 0.200 & 0.050 & 0.197 & \\
15 & 0.032 & 0.122 & 0.029 & 0.095 & \\
20 & 0.017 & 0.044 & 0.009 & 0.009 & \\
25 & 0.001 & 0.000 & 0.000 & 0.000 & \\
& & $\sum=1.00$ & & $\sum=1.00$ & \\
\hline
\end{tabular}

the weights are conserved, $b$ controls the curvature of the weighting function and equals 1 for linear weighting, $H_{\mathrm{p}}$ is the water equivalent of the belowground hydrogen pools $\left(\mathrm{m}^{3} \mathrm{~m}^{-3}\right), W_{\mathrm{L}}$ is lattice water $\left(\mathrm{m}^{3} \mathrm{~m}^{-3}\right)$, SOM is soil organic matter water equivalent $\left(\mathrm{m}^{3} \mathrm{~m}^{-3}\right)$, $B_{\mathrm{R}}$ is root biomass water equivalent $\left(\mathrm{m}^{3} \mathrm{~m}^{-3}\right)$ and $\theta$ is the gravimetrically determined volumetric soil pore water content $\left(\mathrm{m}^{3} \mathrm{~m}^{-3}\right)$. The original approach by Franz et al. (2012b) was modified by Bogena et al. (2013) using the total hydrogen content of belowground hydrogen pools $H_{\mathrm{p}}$ instead of just using the volumetric soil water content $\theta$. Since $H_{\mathrm{p}}$ changes with soil depth we used an iterative approach to determine the appropriate weights. Starting with an average value for the upper $30 \mathrm{~cm}$ of the soil we computed an effective measurement depth $z^{*}$ and weighted $H_{\mathrm{p}}$ of the different soil depths accordingly. With this new value of $H_{\mathrm{p}}$ we then recomputed $z^{*}$ and the weights. Usually the value of $H_{\mathrm{p}}$ stabilizes after a few iterations. The bulk density $\left(\rho_{\text {bd }}\right)$ of the soil changes with depth and influences the soil moisture measurements too. Therefore it was also being taken into account during the iterative process of determining the effective measurement depth $z^{*}$ and the weighted soil moisture. In this first weighting approach we did not use our depth-specific measurements of $W_{\mathrm{L}}$ and $\mathrm{SOM}+B_{\mathrm{R}}$; instead we assumed an average weight fraction value of combined $W_{\mathrm{L}}+\mathrm{SOM}+B_{\mathrm{R}}$ for the entire $30 \mathrm{~cm}$ soil profile.

2. The second approach (depth-specific weighting, DSW) was identical to the first one (SDW) except for us- ing depth-specific measurements of $W_{\mathrm{L}}$ and $\mathrm{SOM}+B_{\mathrm{R}}$ (see Table 3 for an example).

3. For the third approach (distance-depth weighting, DDW), we adopted the weighting approach described in Köhli et al. (2015). This approach introduces the distance-dependent variable depth weighting where the effective measurement depth decreases with distance from the sensor. The effective measurement depth $z^{*}$ is calculated according to

$z^{*}=\rho_{\mathrm{bd}}^{-1}\left[8.32+0.14 \cdot\left(0.97+e^{\frac{-r}{100}}\right) \cdot \frac{26.42+H_{\mathrm{p}}}{0.057+H_{\mathrm{p}}}\right]$,

where $\rho_{\mathrm{bd}}$ is the bulk density of the soil $\left(\mathrm{g} \mathrm{cm}^{-3}\right), r$ is the radial distance (in $\mathrm{m}$ ) from the CRS and $H_{\mathrm{p}}$ is the water equivalent of the belowground hydrogen pools $\left(\mathrm{m}^{3} \mathrm{~m}^{-3}\right)$ (see Eq. 8). This approach also assumes that the footprint size of the sensor varies with soil water content and atmospheric water content. We computed the varying footprint diameter for each calibration campaign and weighted the samples from 25,75 and $200 \mathrm{~m}$ accordingly.

4. The fourth approach (distance-depth weighting, nonlinear, DDWnl) was identical to the third one (DDW) except for using the nonlinear depth-weighting function recommend by Köhli et al. (2015) instead of the linear one (from Eq. 5):

$\mathrm{wt}(z)=e^{\frac{-2 z}{z^{*}}}$ 


\subsection{Estimation of biomass and influence of seasonal changes in biomass}

Biomass influences neutron counts due to its hydrogen content. In order to test (and potentially exclude) the influence of seasonal changes in aboveground forest biomass, we estimated living tree biomass and tree biomass changes throughout the year by applying the aboveground dry biomass functions for beech forest (Fagus sylvatica $\mathrm{L}$.) from Santa Regina et al. (1997):

$$
\begin{aligned}
& B_{\mathrm{S}}=0.0894 \cdot \mathrm{DBH}^{2.4679}, \\
& B_{\mathrm{B}}=0.0317 \cdot \mathrm{DBH}^{2.3931}, \\
& B_{\mathrm{L}}=0.0145 \cdot \mathrm{DBH}^{1.9531} .
\end{aligned}
$$

$B_{\mathrm{S}}$ is dry stem biomass $\left(\mathrm{kg}\right.$ tree $\left.{ }^{-1}\right), B_{\mathrm{B}}$ dry branch biomass $\left(\mathrm{kg}\right.$ tree $\left.^{-1}\right), B_{\mathrm{L}}$ dry leaf biomass $\left(\mathrm{kg}\right.$ tree $\left.{ }^{-1}\right)$ and DBH is the diameter of the tree stem at breast height $(\mathrm{cm})$. Total dry aboveground biomass $B_{\mathrm{ag}}$ is the sum of the three components.

To apply these functions, we conducted a survey of tree diameters and tree density in the beech forest that surrounds the CRS. This allowed us to determine both the total biomass of the beech forest, as well as the seasonally variable fraction of biomass (leaf biomass divided by total biomass). We first calculated the water mass ( $W_{\mathrm{agb}}$ ) in stems, branches and leaves - assuming a leaf water content of $0.6 \mathrm{~kg} \mathrm{~kg}^{-1}$ of wet biomass (Gravano et al., 1999) and a wood water content of $0.11 \mathrm{~kg} \mathrm{~kg}^{-1}$ (Bouriaud et al., 2004). Finally, using the mass fraction of hydrogen in water $\left(M_{\mathrm{w}}=0.1119 \mathrm{~kg} \mathrm{H}\right.$ per $\left.\mathrm{kg} \mathrm{H}_{2} \mathrm{O}\right)$ and in dry biomass $\left(M_{\mathrm{b}}=0.0622 \mathrm{~kg} \mathrm{H}\right.$ per kg cellulose: $\left.\mathrm{C}_{6} \mathrm{H}_{10} \mathrm{O}_{5}\right)$ the total hydrogen mass $\left(H_{\mathrm{agb}}\right)$ of aboveground biomass in the beech stand was derived:

$H_{\mathrm{agb}}=W_{\mathrm{agb}} \cdot M_{\mathrm{w}}+B_{\mathrm{ag}} \cdot M_{\mathrm{b}}$.

We did not conduct surveys on the other tree species. Table 1 shows that the beech stand covers $56 \%$ of the footprint area around the CRS (when assuming the exponential distance weighting from Zreda et al., 2008). Pine covers $16 \%$, spruce $13 \%$ and oak $8 \%$. With the new distance weighting function of Köhli et al. (2015), the cover fractions of the other (non-beech) tree species would decrease even further. Also, the seasonal variation in spruce and pine aboveground biomass is very small and thus we consider it to be constant in this study.

\subsection{Validation}

As an objective performance measure to compare the soil moisture time series derived from the CRS with the soil moisture time series from the TDT sensors we used the modified Kling-Gupta efficiency KGE' (Gupta et al., 2009; Kling et al., 2012):
$\mathrm{KGE}^{\prime}=1-\sqrt{(r-1)^{2}+(\beta-1)^{2}+(\gamma-1)^{2}}$,

with correlation coefficient $r$ :

$r=\frac{\sum_{i=1}^{n}\left(x_{i}-\bar{x}\right)\left(y_{i}-\bar{y}\right)}{\sqrt{\sum_{i=1}^{n}\left(x_{i}-\bar{x}\right)^{2}} \cdot \sqrt{\sum_{i=1}^{n}\left(y_{i}-\bar{y}\right)^{2}}}$,

bias ratio $\beta=\mu_{\mathrm{mod}} / \mu_{\mathrm{obs}}$ and variability ratio $\gamma=\left(\sigma_{\bmod } / \mu_{\text {mod }}\right) /\left(\sigma_{\mathrm{obs}} / \mu_{\mathrm{obs}}\right)$. The $\mathrm{KGE}^{\prime}$ measures the Euclidian distance in a 3-D space where the correlation coefficient $r$ is on one axis, the variability ratio $\beta$ is on the second axis and the bias ratio $\gamma$ is on the third axis. $\mathrm{KGE}^{\prime}$ scores range from 1 (representing a perfect fit) to $-\infty$. Due to the composite nature of the $\mathrm{KGE}^{\prime}$, it is relatively simple to analyze which feature of the time series (correlation, bias, variability) contributes most to the good/bad performance of a model.

\section{Results}

\subsection{Gravimetric soil water measurements and soil physical characteristics}

Soil water content in the sandy soils ranged between 0.03 and $0.37 \mathrm{~m}^{3} \mathrm{~m}^{-3}$ (absolute minimum and maximum values of individual soil core samples during the 10 sampling campaigns). The spatial distribution of volumetric soil water content for the 10 calibration days is shown in Fig. 3. At each location the soil water content is an unweighted average value of the six samples taken from 0 to $30 \mathrm{~cm}$ depth. The mean volumetric soil water content for the calibration days over all calibration locations ranged from 0.07 up to $0.16 \mathrm{~m}^{3} \mathrm{~m}^{-3}$ with standard deviations ranging from 0.015 to $0.047 \mathrm{~m}^{3} \mathrm{~m}^{-3}$. The depth- and distance-weighted averages used for calibration ranged from 0.08 to $0.24 \mathrm{~m}^{3} \mathrm{~m}^{-3}$ (see for example Table 4, column: $\theta_{\text {depthw }}$ ). A general soil moisture pattern emerged with the soil moisture under coniferous tree stands being lower and under deciduous tree stands being higher. Especially the uppermost soil layer $(0-5 \mathrm{~cm})$ was drier under the coniferous trees - on average about $0.065 \mathrm{~m}^{3} \mathrm{~m}^{-3}$ - while the deeper soil layers under coniferous trees were about $0.023 \mathrm{~m}^{3} \mathrm{~m}^{-3}$ drier. The highest spatial variabilities in soil moisture were encountered during spring and fall seasons and more homogenous soil moisture conditions during winter and summer. The wettest calibration we conducted (WI) yielded an average soil water content of $0.29 \mathrm{~m}^{3} \mathrm{~m}^{-3}$ for the top $5 \mathrm{~cm}$. Calibration at higher soil water content is difficult as it only occurs for short periods of time after large precipitation events when significant amounts of intercepted water are also present in the canopy and litter layer. 


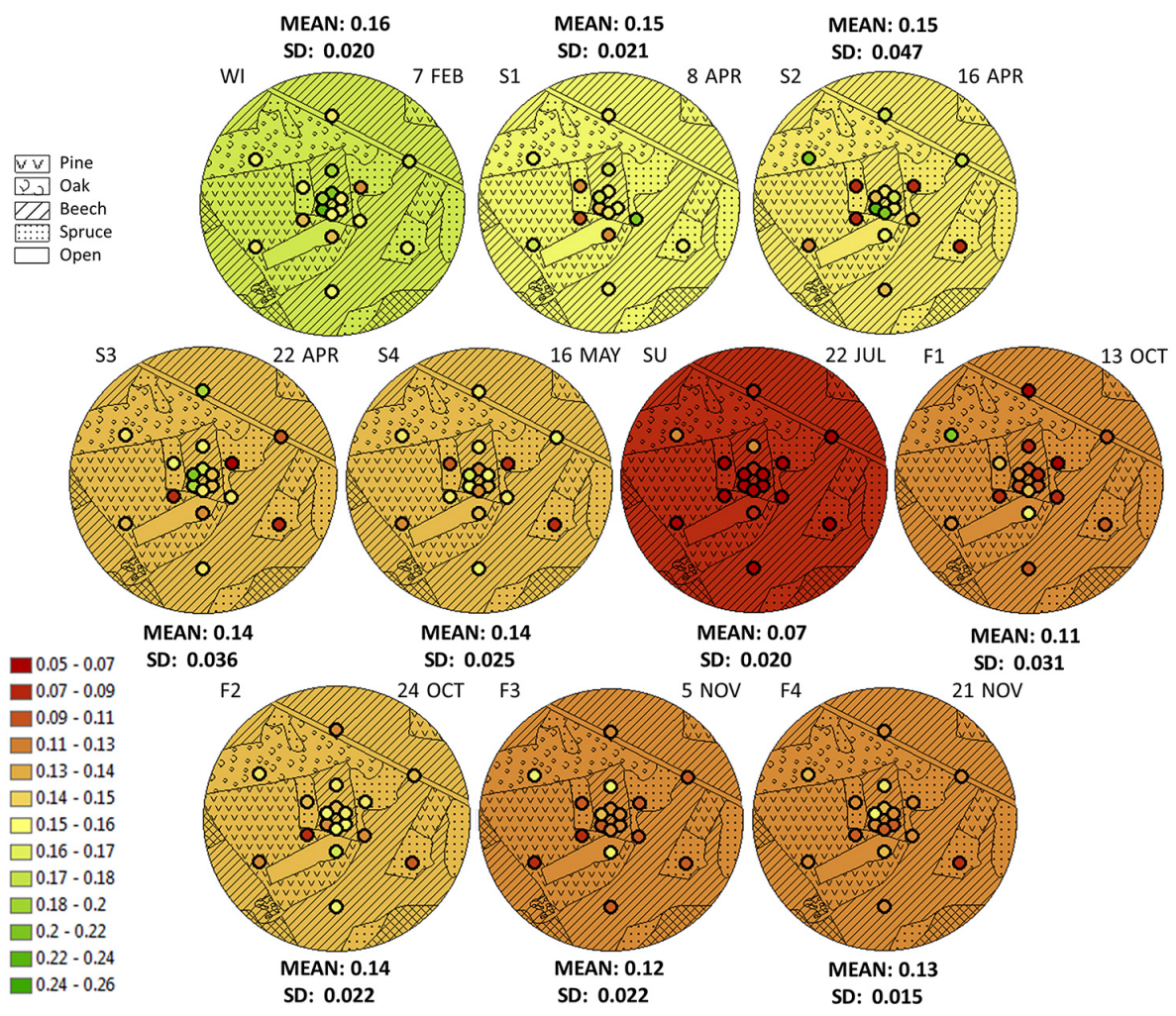

Figure 3. Gravimetrically determined volumetric soil water content patterns in the footprint of the CRS for the 10 calibration dates. The colored dots indicate the unweighted average value from 0 to $30 \mathrm{~cm}$ at the 18 calibration locations. Background colors represent the unweighted average value of all 108 soil samples. Different forest stands (pine, beech, oak, spruce) are indicated by the patterned background.

The average bulk density $\left(\rho_{\mathrm{bd}}\right)$ measurements for the 10 calibration campaigns ranged from 1.16 to $1.22 \mathrm{~g} \mathrm{~cm}^{-3}$ (mean: $1.18 \mathrm{~g} \mathrm{~cm}^{-3}$, standard deviation: $0.02 \mathrm{~g} \mathrm{~cm}^{-3}$ ). The weight fraction of soil organic matter and root biomass water equivalent $\left(\mathrm{wSOM}+B_{\mathrm{R}}\right.$ ) was determined to be $51.4 \mathrm{~g} \mathrm{~kg}^{-1}$ in the shallowest soil layer $(0-5 \mathrm{~cm})$ with decreasing values at depth. The weight fraction of lattice water $\left(\mathrm{w} W_{\mathrm{L}}\right)$ was determined to be $3.2 \mathrm{~g} \mathrm{~kg}^{-1}$ in the shallowest soil layer with slightly increasing values at deeper soil depths.

\subsection{Footprint variability}

The footprint diameters calculated according to Köhli et al. (2015) and used in approaches 3 and 4 ranged from $185 \mathrm{~m}$ for the wettest to $200 \mathrm{~m}$ for the driest conditions. This resulted in distance weights of $\sim 0.56$ (for samples from $25 \mathrm{~m}$ distance), $\sim 0.35$ (for samples from $75 \mathrm{~m}$ distance) and $\sim 0.10$ (for samples from $200 \mathrm{~m}$ distance). These weighting factors varied only marginally between the individual calibration campaigns despite considerable differences in soil and atmospheric water content. Sampling distances with equal weights according to Köhli et al. (2015) would have differed from our sampling pattern $(\sim 1, \sim 33$, $\sim 140 \mathrm{~m}$ instead of $25,75,200 \mathrm{~m}$ ), a condition which we balance by adjusting the distance weights. Furthermore, the con- ditions within $30 \mathrm{~m}$ around our CRS are quite homogenous since the sensor is located within a pure beech stand and we are expecting little difference in average soil moisture content between locations at 1 and $25 \mathrm{~m}$ distance.

\subsection{Calibration}

The average reference atmospheric pressure $\left(P_{0}\right)$ for the entire measurement period was $1005.8 \mathrm{hPa}$; the average reference incoming neutron flux $\left(N_{\text {avg }}\right)$ was 328.3 counts $^{-1}$; the average reference absolute humidity $\left(p_{v 0}^{\text {ref }}\right)$ was $9.1 \mathrm{~g} \mathrm{~m}^{-3}$. Equations (5)-(10) were used to calculate depth-weighted volumetric soil water content $\theta_{\text {depthw }}$ and depth-weighted water equivalent of belowground hydrogen pools $\left(H_{\mathrm{p}}\right)_{\mathrm{depthW}}$, according to the four weighting approaches we applied. Equations (1)-(3) were used to compute $N_{\mathrm{p}}, N_{\mathrm{pi}}$ and $N_{\text {pih }}$, and then Eq. (4) to identify $N_{0}$ for each calibration. Table 3 provides an example of the depth weighting following approach 2 (DSW with depth-specific values of $W_{\mathrm{L}}$ and $\left.\mathrm{SOM}+B_{\mathrm{R}}\right)$.

The values in Table 3 result in a depth-weighted average volumetric water content $\theta_{\text {depthW }}$ of $0.150 \mathrm{~m}^{3} \mathrm{~m}^{-3}$, a depthweighted water equivalent of belowground hydrogen pools $\left(H_{\mathrm{p}}\right)_{\text {depthW }}$ of $0.179 \mathrm{~m}^{3} \mathrm{~m}^{-3}$ and a depth-weighted bulk density $\left(\rho_{\mathrm{bd}}\right)_{\mathrm{depthW}}$ of $0.981 \mathrm{~g} \mathrm{~cm}^{-3}$. If $W_{\mathrm{L}}$ and $\mathrm{SOM}+B_{\mathrm{R}}$ were 
Table 4. Atmospheric and soil parameters as well as neutron counts for the 10 calibrations. Atmospheric pressure $P$, absolute humidity $p_{v 0}$, raw neutron count $N_{\text {raw }}$, pressure corrected neutron count $N_{\mathrm{p}}$, pressure and incoming radiation corrected neutron count $N_{\text {pi }}$, pressure, incoming radiation and water vapor corrected neutron count $N_{\text {pih }}$, calibration neutron count $N_{0}$, incoming radiation from the neutron monitor $N_{\mathrm{nm}}$, average soil moisture of the top $30 \mathrm{~cm} \theta_{30 \mathrm{~cm}}$, depth-weighted soil moisture $\theta_{\text {depthW }}$, depth-weighted sum of volumetric lattice water content, soil organic matter and root biomass water equivalent $\left(W_{\mathrm{L}}+\mathrm{SOM}+B_{\mathrm{R}}\right)_{\mathrm{depthW}}$, depth-weighted water equivalent of belowground hydrogen pools $\left(H_{\mathrm{p}}\right)_{\text {depthW }}$, depth-weighted bulk density $\left(\rho_{\mathrm{bd}}\right)_{\text {depthW }}$ and average volumetric soil water content $\theta_{\text {mod }}$ of the resulting time series using the $N_{0}$-calibration function with standard parameters. Mean $(\mu)$ and standard deviation $(\sigma)$ values of the 10 calibration campaigns are given in the two bottom lines.

\begin{tabular}{|c|c|c|c|c|c|c|c|}
\hline Calibration & $\begin{array}{c}P \\
(\mathrm{hPa})\end{array}$ & $\begin{array}{c}p_{v 0} \\
\left(\mathrm{~g} \mathrm{~m}^{-3}\right)\end{array}$ & $\begin{array}{c}N_{\text {raw }} \\
\left(\text { counts h }^{-1}\right)\end{array}$ & $\begin{array}{c}N_{\mathrm{p}} \\
\left(\text { counts } \mathrm{h}^{-1}\right)\end{array}$ & $\begin{array}{c}N_{\mathrm{pi}} \\
\left(\text { counts h}^{-1}\right)\end{array}$ & $\begin{array}{c}N_{\text {pih }} \\
\left(\text { counts h }^{-1}\right)\end{array}$ & $\begin{array}{c}N_{0} \\
(\text { counts h } \\
-1\end{array}$ \\
\hline Winter & 984.0 & 5.7 & 606.2 & 514.9 & 518.8 & 509.4 & 872.4 \\
\hline Spring1 & 999.3 & 8.6 & 549.2 & 523.0 & 527.5 & 526.2 & 868.7 \\
\hline Spring2 & 1021.0 & 4.9 & 491.1 & 550.6 & 542.8 & 530.5 & 871.1 \\
\hline Spring3 & 1002.9 & 9.6 & 544.7 & 533.1 & 539.9 & 541.5 & 869.2 \\
\hline Spring4 & 1019.0 & 8.0 & 503.4 & 556.0 & 549.4 & 546.1 & 879.0 \\
\hline Summer & 1008.7 & 14.0 & 613.3 & 626.6 & 623.8 & 640.5 & 858.2 \\
\hline Fall1 & 998.7 & 11.5 & 624.7 & 592.4 & 593.8 & 601.5 & 909.5 \\
\hline Fall2 & 1014.1 & 7.8 & 509.3 & 542.1 & 546.7 & 542.8 & 876.2 \\
\hline Fall3 & 990.3 & 8.5 & 630.4 & 561.4 & 580.4 & 578.5 & 892.8 \\
\hline Fall4 & 1016.7 & 6.6 & 544.4 & 591.0 & 577.7 & 569.9 & 885.7 \\
\hline$\mu$ & 1005.5 & 8.5 & 561.7 & 559.1 & 560.1 & 558.7 & 878.3 \\
\hline$\sigma$ & 11.9 & 2.6 & 50.2 & 33.1 & 31.1 & 37.5 & 13.8 \\
\hline Calibration & $\begin{array}{c}N_{\mathrm{nm}} \\
\left(\text { counts h}^{-1}\right)\end{array}$ & $\begin{array}{c}\theta_{30 \mathrm{~cm}} \\
\left(\mathrm{~m}^{3} \mathrm{~m}^{-3}\right)\end{array}$ & $\begin{array}{c}\theta_{\text {depthW }} \\
\left(\mathrm{m}^{3} \mathrm{~m}^{-3}\right)\end{array}$ & $\begin{array}{c}\left(W_{\mathrm{L}}+\mathrm{SOM}+\right. \\
\left.B_{\mathrm{R}}\right)_{\text {depthW }} \\
\left(\mathrm{m}^{3} \mathrm{~m}^{-3}\right)\end{array}$ & $\begin{array}{c}\left(H_{\mathrm{p}}\right)_{\text {depthW }} \\
\left(\mathrm{m}^{3} \mathrm{~m}^{-3}\right)\end{array}$ & $\begin{array}{c}\left(\rho_{\mathrm{bd}}\right)_{\mathrm{depthW}} \\
\left(\mathrm{g} \mathrm{cm}^{-3}\right)\end{array}$ & $\begin{array}{c}\theta_{\bmod } \\
\left(\mathrm{m}^{3} \mathrm{~m}^{-3}\right)\end{array}$ \\
\hline Winter & 325.8 & 0.163 & 0.228 & 0.0343 & 0.262 & 0.985 & 0.141 \\
\hline Spring1 & 325.5 & 0.153 & 0.200 & 0.0340 & 0.234 & 1.013 & 0.143 \\
\hline Spring2 & 333.0 & 0.150 & 0.185 & 0.0311 & 0.216 & 0.955 & 0.137 \\
\hline Spring3 & 324.1 & 0.140 & 0.175 & 0.0324 & 0.207 & 1.000 & 0.143 \\
\hline Spring4 & 332.2 & 0.139 & 0.170 & 0.0302 & 0.200 & 0.957 & 0.145 \\
\hline Summer & 329.8 & 0.073 & 0.080 & 0.0278 & 0.108 & 1.074 & 0.151 \\
\hline Fall1 & 327.4 & 0.112 & 0.137 & 0.0299 & 0.167 & 1.016 & 0.182 \\
\hline Fall2 & 325.5 & 0.140 & 0.174 & 0.0310 & 0.205 & 0.970 & 0.144 \\
\hline Fall3 & 317.5 & 0.119 & 0.149 & 0.0316 & 0.181 & 1.018 & 0.166 \\
\hline Fall4 & 335.8 & 0.126 & 0.150 & 0.0293 & 0.179 & 0.981 & 0.155 \\
\hline$\mu$ & 327.7 & 0.131 & 0.165 & 0.0312 & 0.196 & 0.997 & 0.151 \\
\hline$\sigma$ & 5.0 & 0.024 & 0.038 & 0.0019 & 0.039 & 0.034 & 0.013 \\
\hline
\end{tabular}

not considered, the values for $\theta_{\text {depthW }}$ and $\left(\rho_{\text {bd }}\right)_{\text {depthW would }}$ change to $0.146 \mathrm{~m}^{3} \mathrm{~m}^{-3}$ and $1.013 \mathrm{~g} \mathrm{~cm}^{-3}$, respectively, because the effective measurement depth $z^{*}$ increases when the higher amounts of $\mathrm{SOM}+B_{\mathrm{R}}$ in the shallow layers are not considered, thus giving more weight to low soil moisture values in deeper soil horizons.

Table 4 lists the parameters relevant for calibration for all 10 calibration dates (again following approach 2, DSW, with depth-specific values of $W_{\mathrm{L}}$ and $\mathrm{SOM}+B_{\mathrm{R}}$ ).

Following the standard $N_{0}$-calibration approach of Desilets et al. (2010), we should have ended up with the same $N_{0}$ value for each of the 10 calibrations. However, the $N_{0}$ range we found was considerable - e.g., from 808 to 895 counts $^{-1}$ for the DDW approach (mean: 841.9 counts $\mathrm{h}^{-1}$, standard deviation: 13.7 counts $^{-1}$ ). As a consequence, the 10 computed time series also showed differences in volumetric soil water content (Fig. 4 illustrates results for the DDW approach). In the most extreme case, these differences were larger than $0.1 \mathrm{~m}^{3} \mathrm{~m}^{-3}$ (which is equal to $24 \%$ of the total range of soil water content at the site).

In fact, none of the four weighting approaches were able to solve the problem of determining a unique calibration parameter for our field site. All weighting approaches resulted in largely deviating $N_{0}$ values between the individual calibrations (see means and standard deviations in column 1 and 2 of Table 5). This in turn led to differences in the resulting time series of volumetric soil water content (see means and standard deviations in column 3 and 4 of Table 5). 
Table 5. Means $(\mu)$ and standard deviations $(\sigma)$ of calibration parameter $N_{0}$ and means $(\mu)$ and standard deviations $(\sigma)$ of resulting time series of volumetric soil water content $\theta_{\text {mod }}$ for the four weighting approaches with 10 calibration campaigns each.

\begin{tabular}{lcccc}
\hline Approach & $\begin{array}{c}\left(N_{0}\right)_{\mu} \\
\left(\text { counts h}^{-1}\right)\end{array}$ & $\begin{array}{c}\left(N_{0}\right)_{\sigma} \\
\left(\text { counts h}^{-1}\right)\end{array}$ & $\begin{array}{c}\left(\theta_{\text {mod }}\right)_{\mu} \\
\left(\mathrm{m}^{3} \mathrm{~m}^{-3}\right)\end{array}$ & $\begin{array}{c}\left(\theta_{\text {mod }}\right)_{\sigma} \\
\left(\mathrm{m}^{3} \mathrm{~m}^{-3}\right)\end{array}$ \\
\hline 1 SDW & 855.0 & 17.3 & 0.158 & 0.015 \\
2 DSW & 878.3 & 13.8 & 0.151 & 0.013 \\
3 DDW & 841.9 & 13.7 & 0.139 & 0.012 \\
4 DDWnl & 828.1 & 13.3 & 0.134 & 0.012 \\
\hline
\end{tabular}

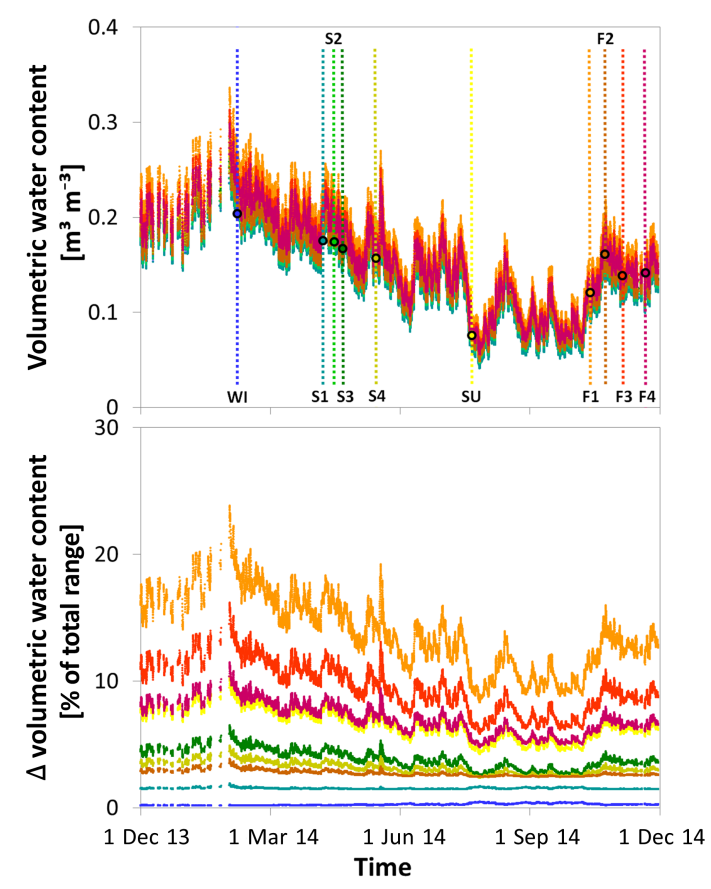

Figure 4. Upper panel: volumetric water content derived from CRS data for each of the 10 calibration dates separately (vertical lines indicate calibration dates, colors correspond to time series colors). Filled circles represent the weighted volumetric water content at the time of calibration (according to DDW). Lower panel: differences in water content between calibration S1 and all other calibrations expressed as a percentage of the total possible range of average soil water content - ranging from 0.04 to $0.34 \mathrm{~m}^{3} \mathrm{~m}^{-3}$ at our field site (color coding corresponds to calibration dates in the upper panel).

\subsection{Modified calibration function}

To include all information of our 10 calibration campaigns into our analysis, we fitted modified calibration functions to four sets of 10 calibration points derived from the four different weighting approaches (see Sect. 3.1). This was done by using the Microsoft Excel Solver software to optimize the three shape parameters $\left(a_{0}, a_{1}, a_{2}\right)$ and $N_{0}$ through the calibration point cloud (solid lines in Fig. 5). Plotting the $N_{\text {pih }}$ values of all 10 calibrations against the gravimetrically determined and depth- (and distance-) weighted volumetric

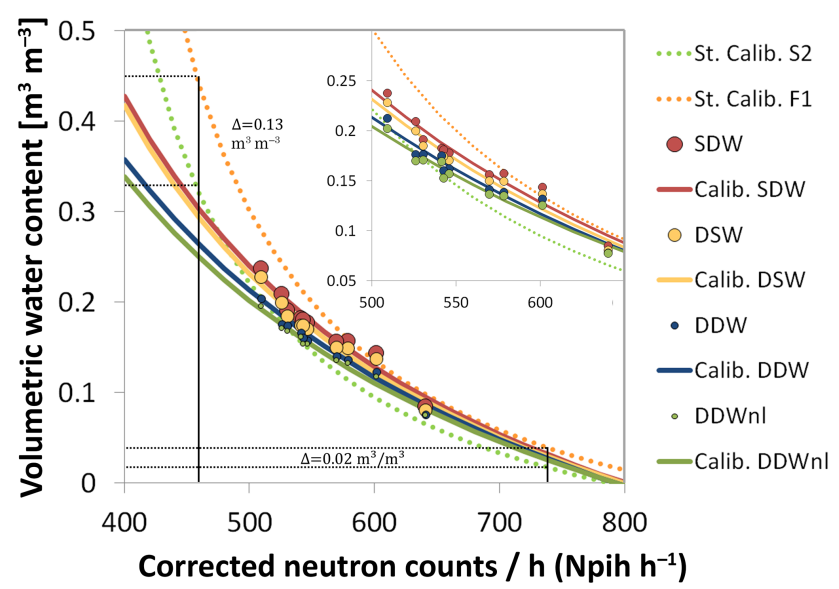

Figure 5. Modified calibration functions (solid lines) for the four different weighting approaches (simple depth weighting SDW, depth-specific weighting DSW, distance-depth weighting DDW, distance-depth weighting, nonlinear DDWnl), each one derived from 10 calibration points (circles). Calibration points are better captured by flatter calibration functions (solid lines) with modified calibration parameters than by any of the standard calibration functions (dotted lines) based on a single calibration data set only (days S2 and F1 as an example). Black lines illustrate that differences in soil moisture between the results of individual calibrations are larger when soil moisture is high. The inset magnifies the area around the calibration points.

soil moisture revealed that the standard shape of the soil moisture-neutron count relation is not valid at our field site. Instead of plotting along functions defined by the standard calibration (Desilets et al., 2010) (examples are dotted lines in Fig. 5) our calibration points are better captured by less steep functions (solid lines in Fig. 5 are the best-fit calibration functions for the different approaches). Using the $N_{0^{-}}$ calibration function with the standard shape parameters may lead to large soil water content deviations between individual calibration campaigns, especially under wet soil moisture conditions. The slope of the $N_{0}$-calibration function is essentially too steep, which means that in our environment a change in the neutron count is caused by a more subtle change in soil moisture than is assumed by the standard relationship - essentially the sensor has a higher sensitivity than one would expect.

The optimized parameters for the four approaches are shown in Table 6 . The resulting soil moisture time series are shown in Fig. 6.

\subsection{Validation}

We tested whether the modified calibration functions improved the performance of the CRS measurements relative to in situ measurements and, if so, which of the weighting approaches performed best. In order to do that we compared the soil moisture time series from the CRS (using the stan- 
Table 6. Modified calibration parameters for the four weighting approaches.

\begin{tabular}{lcccc}
\hline & $N_{0}$ & $a_{0}$ & $a_{1}$ & $a_{2}$ \\
\hline 1 SDW & 926.3 & 0.203 & 0.109 & 0.238 \\
2 DSW & 1007.8 & 0.203 & 0.114 & 0.267 \\
3 DDW & 810.7 & 0.326 & 0.001 & 0.310 \\
4 DDWnl & 779.3 & 0.314 & 0.001 & 0.285 \\
\hline
\end{tabular}

dard $N_{0}$-calibration function from Desilets et al. (2010) and applying our newly derived corrected relationships) with the soil moisture time series from the TDT sensors distributed throughout the footprint. As a first step, the CRS measurements had to be converted to a soil water content value representative of the top $15 \mathrm{~cm}$ of the soil (the integration depth of the TDT sensors). For this purpose we compared the weighted volumetric water content $\left(\theta_{\text {depthw }}\right)$ from the gravimetric measurements of the calibration campaigns (basically what the CRS is supposed to "see") with the unweighted average gravimetric measurements of the top $15 \mathrm{~cm}\left(\theta_{15 \mathrm{~cm}}\right)$ (Fig. S2). We found strong linear correlations for two of the weighting approaches (SDW and DSW) with CRS water content being larger than the $\theta_{15} \mathrm{~cm}$ values and increasing differences for wetter soil conditions (indicating that for higher soil moisture the CRS overestimates soil water contents in the top $15 \mathrm{~cm}$ while for lower soil moisture the overestimation decreases). For approaches 3 and 4 (DDW and DDWnl) offsets of 0.006 and $0.011 \mathrm{~m}^{3} \mathrm{~m}^{-3}$ indicated slightly lower weighted soil water content than the unweighted top $15 \mathrm{~cm}$ values. The linear correlations for the first two weighting approaches were expected, since when it is wetter the effective measurement depth is reduced for the CRS measurements and the wetter shallower soil layers receive more weight. Therefore, the CRS measurements result in higher soil water content than the gravimetric measurements. However, it seems that in approaches 3 and 4 the distance weighting counters this effect. A probable explanation is that the formula used for the distance-depth weighting increases the effective measurement depth. This causes higher weights for deeper (drier) soil layers even under wet conditions and could counteract the trend. We then converted the CRS time series by the above relationships into time series that were representative of the top $15 \mathrm{~cm}$ and compared them to the TDT measurements. The $\mathrm{KGE}^{\prime}$ was used as a performance measure. The worst performance was achieved by the simple depth weighting approach $\left(\mathrm{KGE}^{\prime}(\mathrm{SDW})=0.83\right.$, Table 7$)$, the performance improved when depth-specific weighting was included $\left(\mathrm{KGE}^{\prime}(\mathrm{DSW})=0.88\right)$ and it further improved when including distance weighting $\left(\mathrm{KGE}^{\prime}(\mathrm{DDW})=0.89\right)$. The linear depth weighting worked better than the nonlinear depth weighting $\left(\mathrm{KGE}^{\prime}(\mathrm{DDWnl})=0.83\right)$. That means that the distance-depth-weighting approach improved the neutron sensors performance the most. In comparison, using

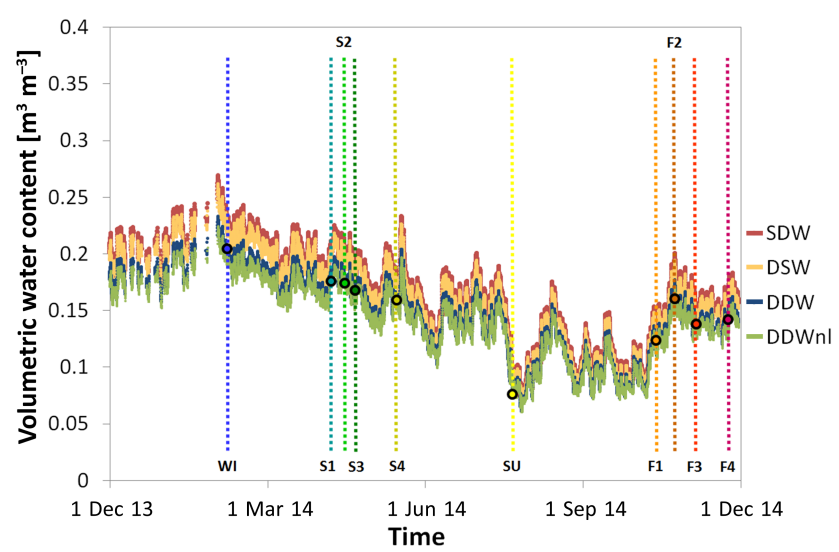

Figure 6. Time series of volumetric water content derived from modified calibration functions using parameters based on the four calibration approaches: simple depth weighting (SDW), depthspecific weighting (DSW), distance-depth weighting (DDW) and distance-depth weighting, nonlinear (DDWnl). Filled circles represent the weighted average of volumetric water content obtained from soil cores at the time of calibration (weighting according to DDW).

the single-point standard $N_{0}$-calibration function and DDW yielded KGE's for the individual calibration campaigns ranging from 0.58 to 0.83 with a mean $\mathrm{KGE}^{\prime}$ of $0.71( \pm 0.08)$. It is important to note that all of the modified calibration approaches performed better than their standard calibration counterparts. The improvement of performance of the new $N_{0}$-calibration functions compared to the standard calibration functions was caused by the better agreement of both the bias ratios $\beta$ and the variability ratios $\gamma$, i.e., both the means and the variabilities of the CRS time series better matched the in situ TDT observations (see also Fig. 7). This supports the hypothesis that at our field site larger than expected changes in neutron count are already caused by subtle changes in soil moisture.

\subsection{Optimizing calibration efforts}

We further tested whether two or more individual calibration campaigns are required to determine a comprehensive calibration function shape, and under which soil moisture conditions these calibrations should be conducted. We paired each individual calibration point (derived from the bestperforming weighting approach, DDW) with all the other calibration points (WI and S1, WI and S2, WI and S3, etc.) and computed best-fit calibration functions for all of these pairings (Fig. 8).

Then we used the resulting calibration functions to convert the measured neutron counts into time series of volumetric soil water content and compared these to the in situ TDT measurements (again using the $\mathrm{KGE}^{\prime}$ as the performance measure). We found that a two-point calibration proved to be sufficient in the case where the difference in soil water con- 
Table 7. Performance measures for the four weighting approaches - comparison of modified calibration (mdf) with standard calibration (stan). $\mathrm{KGE}^{\prime}$ is the modified Kling-Gupta efficiency, $\beta$ is the bias ratio and $\gamma$ is the variability ratio. $\left(\mathrm{KGE}^{\prime}\right)_{\mu}$ and $\left(\mathrm{KGE}^{\prime}\right)_{\sigma} \mathrm{represent}$ the mean and standard deviation of the $\mathrm{KGE}^{\prime}$ values of the 10 individual single-point standard calibrations.

\begin{tabular}{lccccccc}
\hline & $\begin{array}{c}\mathrm{KGE}^{\prime} \\
\text { mdf }\end{array}$ & $\begin{array}{c}\beta \\
\text { mdf }\end{array}$ & $\begin{array}{c}\gamma \\
\text { mdf }\end{array}$ & $\begin{array}{c}\left(\mathrm{KGE}^{\prime}\right. \\
\text { stan })_{\mu}\end{array}$ & $\begin{array}{c}\left(\mathrm{KGE}^{\prime}\right. \\
\text { stan })_{\sigma}\end{array}$ & $\begin{array}{c}(\beta \\
\text { stan })_{\mu}\end{array}$ & $\begin{array}{c}(\gamma \\
\text { stan })_{\mu}\end{array}$ \\
\hline 1 SDW & 0.830 & 0.849 & 0.986 & 0.675 & 0.045 & 1.120 & 1.258 \\
2 DSW & 0.880 & 0.915 & 0.964 & 0.727 & 0.035 & 1.032 & 1.231 \\
3 DDW & 0.891 & 1.076 & 0.986 & 0.712 & 0.081 & 0.878 & 1.237 \\
4 DDWnl & 0.833 & 1.148 & 1.011 & 0.681 & 0.096 & 0.818 & 1.244 \\
\hline
\end{tabular}

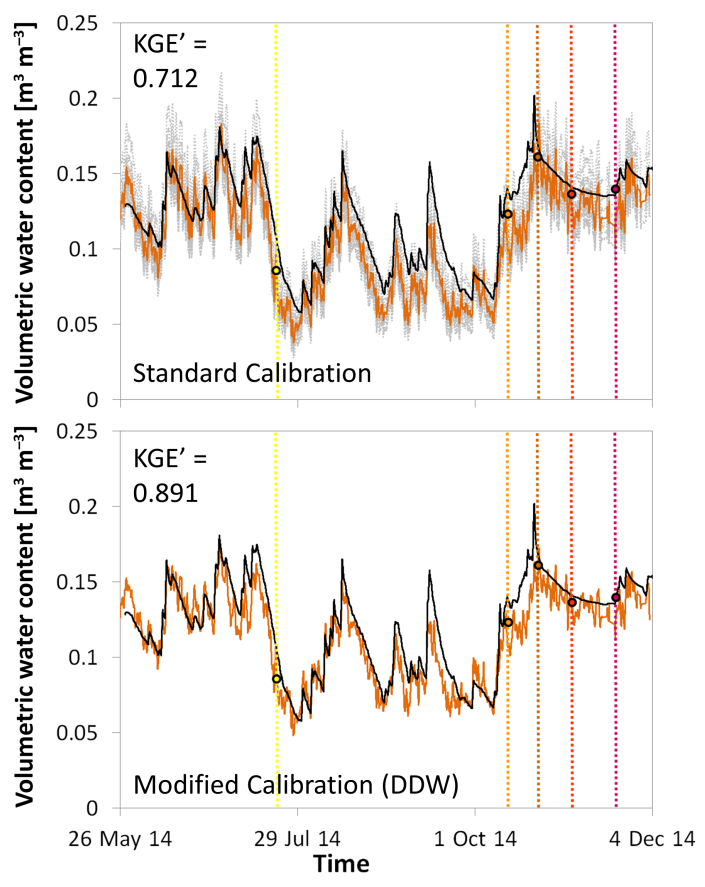

Figure 7. Average volumetric water content derived from TDT point measurements (black line) and CRS measurements (orange line) using different calibration functions. Upper panel: the orange line is an average of the volumetric water content derived from the 10 calibration campaigns of the CRS, using the standard $N_{0^{-}}$ calibration function from Desilets et al. (2010) applying the DDW approach. Grey dotted lines are results for 10 individual calibration campaigns ( $\mathrm{KGE}^{\prime}$ values range from 0.579 to 0.834 ). Lower panel: the orange line is the volumetric water content derived from the calibration function with modified calibration parameters applying the DDW weighting approach based on all 10 calibration dates. The colored vertical lines mark the days of the last five calibration campaigns.

tent between the two calibrations was larger than $0.1 \mathrm{~m}^{3} \mathrm{~m}^{-3}$ (i.e., for our sandy soils it covered $\sim 50 \%$ of the observed range of average soil water content). Figure 9 indicates that the calibrated neutron count-soil water content conversion will always perform well if the soil moisture difference between the two calibrations is sufficiently large. Also, it turned out to be more important to capture a calibration point at

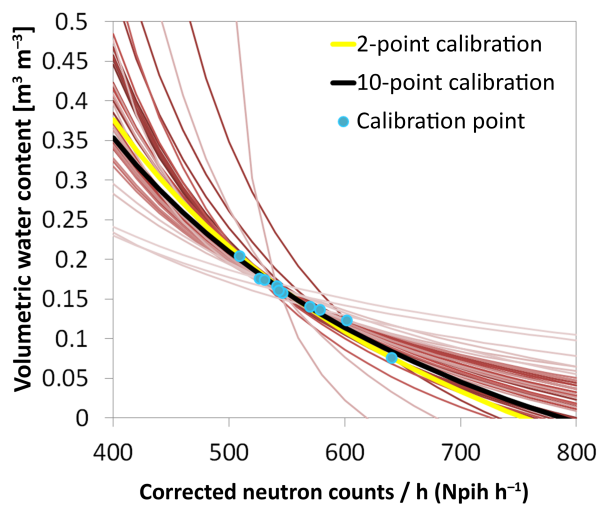

Figure 8. Best-fit $N_{0}$-calibration functions (red-brown colored lines) for all combinations of two-point calibrations (blue dots). Best-fit $N_{0}$-calibration function for 10-point calibration (black line). Best-fit two-point $N_{0}$-calibration function derived from calibration points with the highest and lowest volumetric water content (yellow line).

very dry rather than at very wet soil water contents. This is illustrated in Fig. 9 where predominantly calibrations that involve low soil water contents (red dots) as the minimum value achieve $\mathrm{KGE}^{\prime}$ s of 0.9 while these $\mathrm{KGE}^{\prime}$ values are also achieved more frequently with intermediate soil water contents (light blue dots) as the maximum value.

\subsection{Variability of hydrogen pools}

The tree survey revealed a median diameter of $23.9 \mathrm{~cm}$ (min: $3.2 \mathrm{~cm}, Q_{25}: 11.5 \mathrm{~cm}, Q_{75}: 43.7 \mathrm{~cm}$, $\left.\max : 93.3 \mathrm{~cm}\right)$ and a tree density of 0.05 stems $\mathrm{m}^{-2}$. With these values at hand and Eqs. (11)-(13), the dry aboveground biomass of the beech stand $\left(B_{\mathrm{ag}}\right.$ ) was $63.8 \mathrm{~kg} \mathrm{~m}^{-2}$ (with $62.8 \mathrm{~kg} \mathrm{~m}^{-2}$ from stem and branches and $1.0 \mathrm{~kg} \mathrm{~m}^{-2}$ from leaves) (Fig. 10). These values result in $9.2 \mathrm{~kg} \mathrm{~m}^{-2}$ of biomass water $\left(W_{\mathrm{agb}}\right)$ (with $7.8 \mathrm{~kg} \mathrm{~m}^{-2}$ from stem and branches and $1.5 \mathrm{~kg} \mathrm{~m}^{-2}$ from leaves). Further calculations yield a hydrogen mass of $4.8 \mathrm{~kg} \mathrm{~m}^{-2}$ for stem and branches and a hydrogen mass of $0.22 \mathrm{~kg} \mathrm{~m}^{-2}$ for leaves (Eq. 14). Other hydrogen pools within the CRS footprint were also assessed. The thickness of the litter layer was determined to be $5 \mathrm{~cm}$ on average. Assuming a porosity of $85 \%$ yields a hydrogen mass 
Table 8. Hydrogen pools (in $\mathrm{kg}$ hydrogen per $\mathrm{m}^{2}$ ) in the CRS footprint for different moisture conditions (wet: $0.29 \mathrm{~m}^{3} \mathrm{~m}^{-3}$, full canopy and litter storage; intermediate: $0.17 \mathrm{~m}^{3} \mathrm{~m}^{-3}$, dry canopy and moist litter storage; dry: $\left.0.05 \mathrm{~m}^{3} \mathrm{~m}^{-3}\right)$. Aboveground biomass is split into a static part (AGB wet static) comprising stems, branches and dry litter and a variable part (AGB wet variable) that represents leaves.

\begin{tabular}{lccc}
\hline Hydrogen pool & $\begin{array}{c}\text { Wet } \\
\left(\mathrm{kg} \mathrm{m}^{-2}\right)\end{array}$ & $\begin{array}{c}\text { Intermediate } \\
\left(\mathrm{kg} \mathrm{m}^{-2}\right)\end{array}$ & $\begin{array}{c}\text { Dry } \\
\left(\mathrm{kg} \mathrm{m}^{-2}\right)\end{array}$ \\
\hline AGB wet static & 5.24 & 5.24 & 5.24 \\
AGB wet variable & 0.22 & 0.22 & 0.22 \\
SOM + $R_{\mathrm{B}}$ & 0.36 & 0.44 & 0.66 \\
Lattice water & 0.05 & 0.07 & 0.15 \\
Pore water & 4.12 & 3.26 & 1.77 \\
Litter water & 0.31 & 0.11 & 0.00 \\
Interception & 0.17 & 0.00 & 0.00 \\
\hline Total & 10.47 & 9.35 & 8.04 \\
\hline
\end{tabular}

of $0.47 \mathrm{~kg} \mathrm{~m}^{-2}$ for a dry litter layer. Hence, the hydrogen mass of the static biomass (stems, branches and dry litter) amounted to $5.24 \mathrm{~kg} \mathrm{~m}^{-2}$. Beech litter was found to have a maximum interception capacity of $2.8 \mathrm{~mm}$ in a forest in Luxembourg (Gerrits et al., 2010) corresponding to an additional $0.31 \mathrm{~kg} \mathrm{~m}^{-2}$ of hydrogen when the litter layer is wet. The canopy interception of beech can be assumed to be up to $1.5 \mathrm{~mm}$ (Gerrits et al., 2010) (i.e., another $0.17 \mathrm{~kg} \mathrm{~m}^{-2}$ of hydrogen is added to the system when the canopy is wet). The hydrogen contribution of soil organic matter and root biomass changes with soil water content because the effective measurement depth of the sensor changes. Applying the DDW approach we computed a value of $0.36 \mathrm{~kg} \mathrm{~m}^{-2}$ for wet conditions $\left(0.29 \mathrm{~m}^{3} \mathrm{~m}^{-3}\right)$, a value of $0.44 \mathrm{~kg} \mathrm{~m}^{-2}$ for intermediate conditions $\left(0.17 \mathrm{~m}^{3} \mathrm{~m}^{-3}\right)$ and a value of $0.66 \mathrm{~kg} \mathrm{~m}^{-2}$ for dry conditions $\left(0.05 \mathrm{~m}^{3} \mathrm{~m}^{-3}\right)$. The hydrogen contribution of lattice water also changes with moisture conditions (wet: $0.05 \mathrm{~kg} \mathrm{~m}^{-2}$; intermediate: $0.07 \mathrm{~kg} \mathrm{~m}^{-2}$; dry: $0.15 \mathrm{~kg} \mathrm{~m}^{-2}$ ). A pore water content of $0.29 \mathrm{~m}^{3} \mathrm{~m}^{-3}$ equals a hydrogen mass of $4.12 \mathrm{~kg} \mathrm{~m}^{-2}$, a pore water content of $0.17 \mathrm{~m}^{3} \mathrm{~m}^{-3}$ equals a hydrogen mass of $3.26 \mathrm{~kg} \mathrm{~m}^{-2}$ and a pore water content of $0.05 \mathrm{~m}^{3} \mathrm{~m}^{-3}$ reduces the hydrogen mass to $1.77 \mathrm{~kg} \mathrm{~m}^{-2}$. Figure 11 and Table 8 give an overview of the different hydrogen pools for varying moisture conditions within the footprint of the CRS.

\section{Discussion}

\subsection{Potential influences on neutron counts}

The $10 N_{0}$-calibration parameters derived from our $10 \mathrm{cal}-$ ibrations varied considerably. In a first analysis, we found that this was not related to the different soil moisture conditions during calibration. In search of other potentially unac-

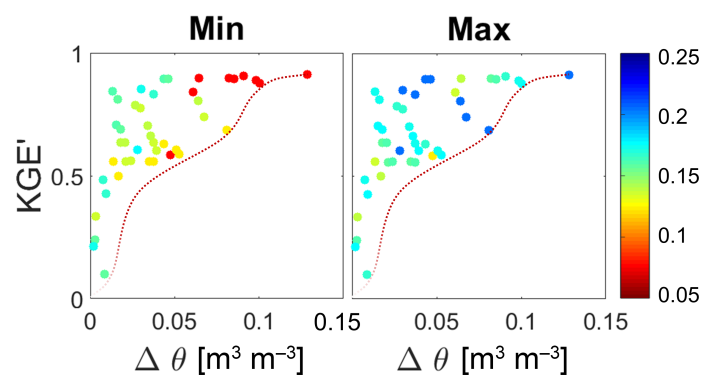

Figure 9. Performance of CRS soil water content data derived from two-point calibrations in relation to difference between soil moisture states $(\Delta \theta)$ at the two calibration dates. The color bar indicates volumetric soil water content. Left panel: points are colored according to the soil water content of the drier calibration date. Right panel: points are colored according to the soil water content of the wetter calibration date. Dashed lines indicate that soil moisture differences of less than $0.1 \mathrm{~m}^{3} \mathrm{~m}^{-3}$ can produce $N_{0}$-calibration curves with sub-optimal conversions of neutron counts to volumetric soil water content.

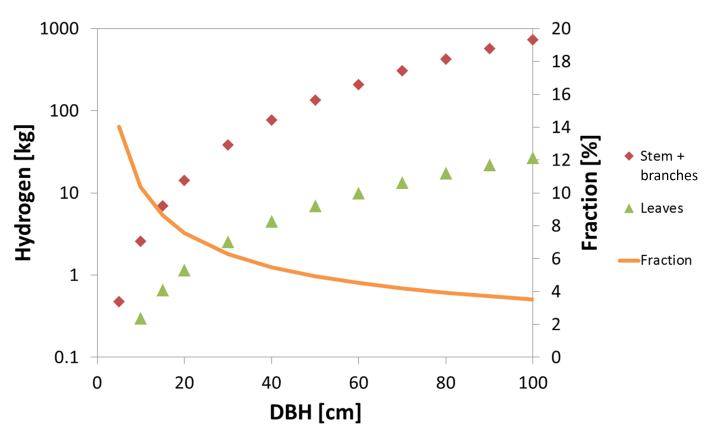

Figure 10. Mass of hydrogen in individual beech trees in stem and branches (red diamonds) and leaves (green triangles) in relation to diameter at breast height (DBH). Fraction of leaf hydrogen mass to total aboveground tree hydrogen mass (orange line).

counted factors that influence the neutron count we compared $N_{0}$ values obtained from the 10 calibrations with apparent atmospheric pressure, specific humidity, temperature and estimates of forest crown cover (derived from photographs taken from the ground aiming at the zenith) during the calibration campaigns. No seasonal or other temporal relationships were found. The contributions of different hydrogen pools (Fig. 11) reveal that a large percentage of hydrogen at our field site stems from the aboveground vegetation (52 to $68 \%$, depending on moisture conditions). Fortunately, most of this hydrogen is static in nature and can be accounted for by the calibration of the CRS. Assuming that the hydrogen content of the stems and branches is constant and only the leaves change seasonally, one is left with a fraction of variable hydrogen in the aboveground biomass that accounts for $2-3 \%$ of the total hydrogen mass. The variability in hydrogen due to foliation and defoliation in the beech forest surrounding the CRS amounts to $0.22 \mathrm{~kg} \mathrm{~m}^{-2}$. This 


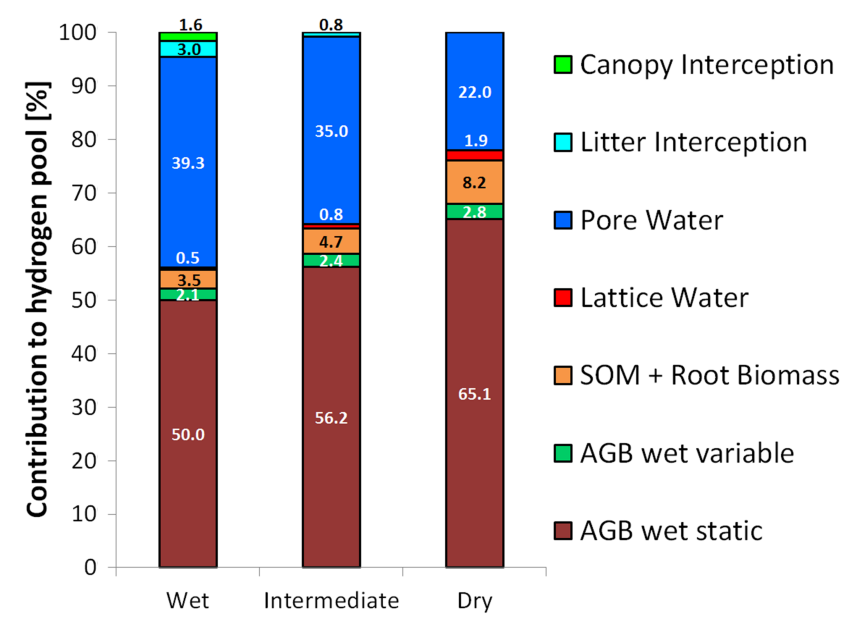

Figure 11. Varying hydrogen pools in the beech forest surrounding the CRS for three different site conditions. AGB (aboveground biomass) wet variable represents hydrogen contained in deciduous leaves (both in the biomass and in the leaf water). AGB wet static comprises hydrogen contained in biomass and water of tree stems and branches as well as in biomass of the litter layer.

means that it equals a change in soil water content of about $0.031 \mathrm{~m}^{3} \mathrm{~m}^{-3}$ (under wet conditions) and $0.018 \mathrm{~m}^{3} \mathrm{~m}^{-3}$ (under dry conditions). These differences for wet and dry conditions are due to the fact that the effective measurement depth $z^{*}$ of the CRS increases for dry conditions: the sensor receives the neutron signal from deeper soil depths and therefore an equal increase in soil water content requires a larger amount of water since a larger soil column has to be filled. At high soil moisture, a $0.01 \mathrm{~m}^{3} \mathrm{~m}^{-3}$ soil moisture change from 0.28 to $0.29 \mathrm{~m}^{3} \mathrm{~m}^{-3}$ equals a change of $0.07 \mathrm{~kg} \mathrm{~m}^{-2}$ of hydrogen in the soil. At low soil moisture, the change from 0.05 to $0.06 \mathrm{~m}^{3} \mathrm{~m}^{-3}$ is equal to a change in hydrogen of $0.12 \mathrm{~kg} \mathrm{~m}^{-2}$. The above calculations with respect to biomass variability disregard the fact that fallen leaves still contain hydrogen (which hence is not completely removed from the system immediately and therefore should also reduce the expected variability). At our field site $65 \%$ of the distance-weighted area surrounding the CRS is covered by deciduous trees (mainly beech and oak), the other $35 \%$ do not experience a significant annual cycle of leaf growth and fall (pine, spruce and grassland). This should further reduce the influence of seasonally variable biomass on the cosmicray neutron counts (with a potential maximum influence of leaf-out during wet conditions of $0.020 \mathrm{~m}^{3} \mathrm{~m}^{-3}$ and only $0.012 \mathrm{~m}^{3} \mathrm{~m}^{-3}$ in dry conditions). In summary, we do not expect a significant impact of seasonally varying aboveground biomass on the measurements of soil water content. Also, we could not find systematic changes in the calibration results connected to the annual cycle of tree foliation/defoliation (i.e., a reduction in counts during summer due to higher hydrogen content in the aboveground biomass). Therefore we deem a correction for variable hydrogen from forest canopy biomass at different times of the year unnecessary.

With regard to other varying hydrogen pools, we noticed that the influence of interception storage both in the canopy and in the litter layer can potentially have an impact. When both the canopy and the litter layer are wet, the combined hydrogen amount within these two stores can sum up to almost $5 \%$ of the total hydrogen pool equaling a change in volumetric soil water content of $0.067 \mathrm{~m}^{3} \mathrm{~m}^{-3}$ (Fig. 11). It is not possible to solve this problem by calibrating during conditions of high interception storage since then the soil water content would be underestimated as soon as the canopy is dry. Calibration during conditions of dry canopy and litter layer is recommendable because conditions with an empty interception store are generally prevalent and can be much better defined than conditions with a filled interception store. A potential solution to the influence of the variable interception storage filling is the introduction of another neutron count correction using observed, derived or modeled interception storage values (similar to the pressure or the water vapor correction).

\subsection{Weighting approaches}

The fact that the DSW approach performed better than the SDW is an indication that the depth variations in lattice water, soil organic matter and root biomass content should be explicitly accounted for during the calibration of the CRS. The best performance was achieved with a weighting approach (DDW) that explicitly takes into account both depth weighting as well as distance weighting of the soil water content (Table 7). This suggests that the variation in the footprint diameter needs to be considered during individual calibration campaigns. Linear depth weighting resulted in a better CRS performance than nonlinear depth weighting since the nonlinear depth weighting basically underestimated soil water contents during wet periods (because higher weights of deeper (drier) soil layers were included). This caused both a decrease in the mean soil water content as well as a decrease in the variability of the soil water content time series and hence reduced the performance of the CRS. In soils where water content increases with depth, the difference between linear and nonlinear depth weighting could be smaller (even negligible). At our field site, however, the decrease of water content with depth apparently favors the use of a linear depth-weighting function.

\subsection{Calibration function}

The differences in calibration results are likely caused by the fact that the shape of the $N_{0}$-calibration function is different at our field site. That means that while being temporally stable the shape of the calibration function is spatially variable - there is no standard curve applicable to all sites. At our site the function is less steep than the standard $N_{0}$-calibration function suggested by Desilets et al. (2010), i.e., a similar in- 
crease in neutron counts is associated with a smaller decrease in soil moisture. A recalibration of the shape of the curve using all calibration points considerably improved the agreement between in situ measurements and CRS measurements of soil moisture. A two-point calibration already proved to be sufficient to define the correct shape of the calibration function given that the soil moisture states at the two calibration times were sufficiently different. In a recent study Iwema et al. (2015) also investigated temporal field sampling strategies for three different calibration methods. They tested combinations of different numbers of random sampling dates and found that using more than six random sampling dates did not improve their calibration results much more. However, for the $N_{0}$-calibration method they found that selecting sampling dates with distinct soil wetness conditions could reduce the required number of samplings. In conclusion they also recommended more than one calibration campaign for the $N_{0}$-calibration approach and argued that the shape of the calibration function should not be fixed but kept variable during the calibration process. This is in line with our findings on the shape of the calibration function. The value of the standard $N_{0}$-calibration method becomes apparent when there is only data available from one calibration date. Due to the fixed shape of its calibration function, the general dynamics of the soil water content will still be reproduced.

We can only speculate about the reasons behind this shape inconsistency of the calibration function for our site since we did not do any theoretical neutron modeling. To our knowledge we are dealing with the lowest number of counts of all published studies (average $N_{0}=878$ counts $^{-1}$, Table 4). Although the calibration function was theoretically developed for all environments it has not yet been tested sufficiently in such low-count, forested environments. Moreover, due to the low neutron count the uncertainty in the determination of soil water content during calibration has a much higher influence on the calibration results than in high-count environments. Bogena et al. (2013) pointed out another complicating factor that is present in forested environments the litter layer. They showed that at their sites $\left(N_{0}: 913\right.$ to 1397 counts $^{-1}$ ), the model-derived water content within the litter layer (under spruce) was subject to much higher variability than the water content in the underlying soil. During wet conditions the water within the litter layer contained $36 \%$ of the hydrogen mass within the footprint of the CRS while during dry conditions it contained only $10 \%$ of the hydrogen mass. This leads to an increase in the variability of the neutron counts and can thus cause an overestimation of soil water content during wet conditions. Although the water within the litter layer at our site accounts for a much smaller fraction of the total hydrogen pool (up to $3 \%$ ) it can still have an influence on the neutron counts and the calibration results. The occurrence of canopy interception would have the same variability-increasing effect on the CRS signal, although it is expected to be significantly smaller than the influence of the litter layer. Baatz et al. (2014) working also in a low-count environment $\left(N_{0}\right.$ : 936 to 1242 counts $\left.^{-1}\right)$ with land use ranging from grassland to agriculture to forest compared the standard $N_{0}$-calibration method to another parameterization method developed by Shuttleworth et al. (2013) (the COSMIC operator, a model of neutron intensity used in data assimilation schemes) and found that the former interpreted dry periods drier and wet periods wetter - which is in accordance to our findings that suggest that the standard $N_{0^{-}}$ calibration function is too steep. Lv et al. (2014), in a study at a mixed-forest/grassland site also recommended more than one calibration. They operated in a high-count environment in Utah $\left(N_{0}=2189\right.$ counts $\left.^{-1}\right)$ and attributed the different shape of their calibration function to binary soil moisture patterns at their site where the grassland soils were much drier than the forest soils under wet conditions but just as dry under dry conditions. Our field site is subject to similar spatial variability since it is also comprised of multiple areas with non-uniform soil water content (mean values of soil water contents differ between different forest stands). Following the argumentation of Lv et al. (2014), the fact that distance weighting improved our results can be regarded as an indication that non-homogeneous soil moisture conditions indeed lead to changes in the shape of the calibration function. At our site, distance weighting reduced the spatial variability within the footprint of the sensor since it assigned higher weights to the closest sampling sites, which were all located in the homogenous and relatively wet beech forest, while the influence of the drier soils under the coniferous trees was reduced.

If it was possible to fully correct for all factors that influence footprint size, depth weighting and neutron count, a one-time calibration of the CRS would be sufficient. However, the abundance of different hydrogen pools and the uncertainties in the sensing depth estimation will always lead to uncertainties in the calibration process. Therefore, we argue that for the use of the CRS as a simple tool to measure soil water content at intermediate scales, the efforts of measuring all necessary parameters are not justified. As shown by Iwema et al. (2015) and by the results of this study, this issue can be dealt with by using site-specific calibration parameters estimated from in situ samples taken during dry and wet conditions. Hence, we recommend a two-point calibration that - although being empirical in nature - inherently incorporates many of the required corrections.

\section{Conclusion}

Our results suggest that a one-time calibration of the CRS using the available neutron count corrections and weighting approaches is not sufficient at our field site. This is mainly due to the fact that the shape of the standard $N_{0}$-calibration function is not able to reproduce the dynamics in soil water content we observed with our network of distributed in situ TDT sensors. Several factors could cause this discrepancy, 
amongst them the presence of a litter layer and spatially heterogeneous soil moisture conditions within the sensor footprint. After calibrating the CRS 10 times in a mixed forest in north-eastern Germany, we found that a two-point calibration already considerably improved the agreement between soil water content derived from in situ TDT measurements and from the CRS, given significantly different moisture conditions during the two calibration periods/campaigns (for a detailed explanation on the procedure see Appendix A). We found that the explicit consideration of depth-specific values of soil organic matter and root biomass improved the calibration results while seasonal changes in aboveground biomass in the forest were found to be negligible. While there is no doubt that further investigations of factors that influence the neutron signal are necessary and useful, it is also apparent that it becomes increasingly difficult to distinguish between the effects of the individual correction factors and the uncertainty caused by all the corrections. Therefore, our goal was to use empirical data to test available methods and combinations thereof and to provide a guideline on how to easily and comprehensively calibrate a CRS in various environments using these methods. Looking beyond that objective, site intercomparison studies along gradients from high to low-count environments and/or from locations with varying litter layers could give rise to the development of simple corrections to the shape of the $N_{0}$-calibration function.
When measuring soil water content with a CRS, it is important to note that over time the measurements are hardly ever representative of the exact same soil segment around and below the sensor (Köhli et al., 2015). With the footprint shrinking and expanding and the effective measurement depth in the soil decreasing and increasing, we have to be careful when interpreting and using our results. If we keep that in mind, however, this new technology will indeed be able to bridge the gap between point in situ and areal remote sensing soil moisture measurements and thus provide a valuable tool for the advancement of hydrologic understanding. 


\section{Appendix A: Proposed method for calibration in forest environments}

We provide an Excel file as a Supplement to perform the calculations described in the following step-by-step instructions.

1. Set up (or use) a weather station that monitors air temperature and relative humidity close to the CRS.

2. Set up the CRS in a location where the conditions within a radius of at least $30 \mathrm{~m}$ around the sensor are relatively homogeneous (similar soils, tree species, expected soil moisture conditions).

3. Switch on the CRS and come back later for calibration (or set it up before 06:00 LT (local time) and start calibrating on the same day). You should at least have $12 \mathrm{~h}$ of CRS data for one calibration. Do not switch it off after the calibration, let it record continuously.

4. Choose a day with very dry or very wet soil moisture conditions for the first calibration campaign and wait for the opposite conditions for your second calibration (this might take a full year to achieve, but you will not lose any data, you will just not be able to accurately convert the data immediately).

5. Choose days without rain or snow for your calibrations, litter and canopy should be dry.

6. Take 108 soil samples from 18 locations (six directions, three distances) and six depths $(0-30 \mathrm{~cm})$. For equal distance weights choose distances according to Köhli et al. (2015) $(\sim 1, \sim 33$ and $\sim 140 \mathrm{~m})$.

7. Weigh the samples the same day you take them, let them oven-dry for $24 \mathrm{~h}$ at $105^{\circ} \mathrm{C}$ and weigh them again to determine the volumetric water content $(\theta)$ and the bulk density $\left(\rho_{\text {bd }}\right)$.

8. Create six bulk samples from the six different soil depths $(2 \mathrm{~g}$ from each of the 18 locations suffices for each soil depth).

9. Determine the combined soil organic matter (SOM) and root biomass $\left(B_{\mathrm{R}}\right)$ content of the six bulk samples by weighing them (after regular oven-drying at $105^{\circ} \mathrm{C}$ ) and then heating them to a temperature of $400^{\circ} \mathrm{C}$ for $24 \mathrm{~h}$ before weighing them again. Convert SOM and $B_{\mathrm{R}}$ to water equivalents by multiplying the weight by 0.556 .

Caution: in clay-rich soils this method tends to overestimate soil organic matter content because some of the lattice water is removed already at temperatures around $400^{\circ} \mathrm{C}$ (Howard and Howard, 1990).
10. Determine the lattice water $\left(W_{\mathrm{L}}\right)$ content of the six bulk samples by weighing them (after SOM and $B_{\mathrm{R}}$ extraction at $400^{\circ} \mathrm{C}$ ) and then heating them to a temperature of $1000^{\circ} \mathrm{C}$ for $24 \mathrm{~h}$ before weighing them again.

Caution: Carbonate-rich soils experience thermal breakdown of carbonates at temperatures above $430^{\circ} \mathrm{C}$ (BenDor and Banin, 1989).

11. Determine the water equivalent of the average hydrogen content of belowground hydrogen pools $\left(H_{\mathrm{p}}\right)$ for each soil depth.

Equation (8).

12. Apply a linear weighting function to your gravimetrically determined $H_{\mathrm{p}}$ measurements accounting for the change in the effective measurement depth $z^{*}$ of the sensor and retrieve a weighted average of $H_{\mathrm{p}}$ within the footprint of the CRS by iteration. Start out by computing the effective measurement depth $z^{*}$ corresponding to your gravimetrically determined values of $H_{\mathrm{p}}$ and $\rho_{\mathrm{bd}}$ averaged over the entire $30 \mathrm{~cm}$. Then apply the weights for the different soil depths $z$ and update the values. Recalculate the effective measurement depth $z^{*}$ and continue this procedure until all values stabilize. Do this for each sampling/calibration distance $(\sim 1, \sim 33$ and $\sim 140 \mathrm{~m}$ ) separately.

Equations (5), (6) and (9).

13. Apply an additional distance weight to the depthweighted volumetric water contents from the different locations in order to account for variations in the footprint size. Also do this iteratively adjusting $H_{\mathrm{p}}$ and the distance weights until both become stable.

Equations are conveniently provided as a Supplement by Köhli et al. (2015) in the form of an Excel file.

14. Use the depth-distance weights to compute weighted values of soil water content $(\theta)$, bulk density $\left(\rho_{\mathrm{bd}}\right)$, lattice water $\left(W_{\mathrm{L}}\right)$, soil organic matter and root biomass water equivalent $\left(\mathrm{SOM}+B_{\mathrm{R}}\right)$.

15. Average raw neutron counts $\left(N_{\text {raw }}\right)$ from the moderated sensor (measuring fast neutrons) over $12 \mathrm{~h}$ with a moving window.

16. Retrieve data from the neutron monitor close to your location in order to correct for the varying intensity of incoming neutrons (you may have to correct this data and fill gaps).

17. Using the entire time series for the period where cosmic-ray data are available determine average atmospheric pressure $\left(P_{0}\right)$, average incoming neutron intensity $\left(N_{\text {avg }}\right)$ and average absolute humidity $\left(p_{v 0}^{\text {ref }}\right)$.

18. Correct raw neutron counts for atmospheric pressure variations $\left(N_{\mathrm{p}}\right)$.

Equation (1). 
19. Correct raw neutron counts for incoming neutron intensity variations $\left(N_{\mathrm{pi}}\right)$.

Equation (2).

20. Correct raw neutron counts for absolute humidity variations $\left(N_{\text {pih }}\right)$.

Equation (3).

21. Fit a function through the two calibration points altering $N_{0}, a_{0}, a_{1}$ and $a_{2}$ (e.g., using Microsoft Excel Solver). When doing this, use average values of the two calibration campaigns for bulk density $\left(\rho_{\mathrm{bd}}\right)$, lattice water $\left(W_{\mathrm{L}}\right)$, soil organic matter and root biomass water equivalent $\left(\mathrm{SOM}+B_{\mathrm{R}}\right)$.
22. Plot the $N_{\text {pih }}$ of both calibrations against the gravimetrically measured, distance- and depth-weighted volumetric soil water content $(\theta)$.

23. Use best-fit parameters to convert time series of $N_{\text {pih }}$ to volumetric soil water content. 


\section{The Supplement related to this article is available online at doi:10.5194/hess-20-1269-2016-supplement.}

Acknowledgements. Funding was provided by the Terrestrial Environmental Observatories (TERENO) and the Virtual Institute for Integrated Climate and Landscape Evolution (ICLEA). We would like to thank the Müritz National Park for allowing us to conduct our research in their forest. Marvin Reich, Iris Heine, Lisei Köhn, Janek Dreibrodt, Stephan Schröder, Erik Reinholz, Christian Rippich, Christopher Gravesen and Jörg Wummel all helped out in the field while Philip Müller and Hans-Peter Nabein assisted in the lab. Gabriele Baroni, Lena Scheiffele and Katja Mroos lent us their field equipment and Martin Schrön provided us with scripts for depth-distance weighting. We thank Heye Bogena and two anonymous referees for their constructive feedback, which helped us a lot to improve the manuscript.

The article processing charges for this open-access

publication were covered by a Research

Centre of the Helmholtz Association.

Edited by: H.-J. Hendricks Franssen

\section{References}

Baatz, R., Bogena, H. R., Hendricks Franssen, H.-J., Huisman, J., Qu, W., Montzka, C., and Vereecken, H.: Calibration of a catchment scale cosmic-ray probe network: A comparison of three parameterization methods, J. Hydrol., 516, 231-244, doi:10.1016/j.jhydrol.2014.02.026, 2014.

Baatz, R., Bogena, H. R., Hendricks Franssen, H.-J., Huisman, J. A., Montzka, C., and Vereecken, H.: An empirical vegetation correction for soil water content quantification using cosmic ray probes, Water Resour. Res., 51, 2030-2046, doi:10.1002/2014WR016443, 2015.

Bachelet, F., Balata, P., Dyring, E., and Iucci, N.: Attenuation coefficients of the cosmic-ray nucleonic component in the lower atmosphere, Il Nuovo Cimento, 35, 23-35, doi:10.1007/BF02734822, 1965.

Ball, D. F.: Loss-on-ignition as an estimate of organic matter and organic carbon in non-calcareous soils, J. Soil Sci., 15, 84-92, 1964.

Baroni, G. and Oswald, S.: A scaling approach for the assessment of biomass changes and rainfall interception using cosmic-ray neutron sensing, J. Hydrol., 525, 264-276, doi:10.1016/j.jhydrol.2015.03.053, 2015.

Ben-Dor, E. and Banin, A.: Determination of organic matter content in arid-zone soils using a simple "loss-on-ignition" method, Commun. Soil Sci. Plan., 20, 1675-1695, 1989.

Bogena, H. R., Huisman, J. A., Baatz, R., Hendricks Franssen, H.-J., and Vereecken, H.: Accuracy of the cosmic-ray soil water content probe in humid forest ecosystems: the worst case scenario, Water Resour. Res., 49, 5778-5791, doi:10.1002/wrcr.20463, 2013.

Bouriaud, O., Bréda, N., Moguédec, G., and Nepveu, G.: Modelling variability of wood density in beech as affected by ring age, radial growth and climate, Trees, 18, 264-276, doi:10.1007/s00468-003-0303-x, 2004.
Coopersmith, E., Cosh, M., and Daughtry, C.: Field-scale moisture estimates using COSMOS sensors: a validation study with temporary networks and Leaf-Area-Indices, J. Hydrol., 519, 637643, doi:10.1016/j.jhydrol.2014.07.060, 2014.

Davies, B. E.: Loss-on-ignition as an estimate of soil organic matter, Soil Sci. Soc. Am. J., 38, 150-151, 1974.

Desilets, D. and Zreda, M.: Spatial and temporal distribution of secondary cosmic-ray nucleon intensities and applications to in situ cosmogenic dating, Earth Planet. Sc. Lett., 206, 21-42, doi:10.1016/S0012-821X(02)01088-9, 2003.

Desilets, D. and Zreda, M.: Footprint diameter for a cosmic-ray soil moisture probe: theory and Monte Carlo simulations, Water Resour. Res., 49, 3566-3575, doi:10.1002/wrcr.20187, 2013.

Desilets, D., Zreda, M., and Ferré, T.: Nature's neutron probe: Land surface hydrology at an elusive scale with cosmic rays, Water Resour. Res., 46, W11505, doi:10.1029/2009WR008726, 2010.

Franz, T., Zreda, M., Ferre, T., Rosolem, R., Zweck, C., Stillman, S., Zeng, X., and Shuttleworth, W.: Measurement depth of the cosmic ray soil moisture probe affected by hydrogen from various sources, Water Resour. Res., 48, W08515, doi:10.1029/2012WR011871, 2012a.

Franz, T., Zreda, M., Rosolem, R., and Ferre, T.: Field validation of a cosmic-ray neutron sensor using a distributed sensor network, Vadose Zone J., 11, doi:10.2136/vzj2012.0046, 2012 b.

Franz, T., Zreda, M., Rosolem, R., and Ferre, T.: A universal calibration function for determination of soil moisture with cosmic-ray neutrons, Hydrol. Earth Syst. Sc., 17, 453-460, doi:10.5194/hess-17-453-2013, 2013.

Gerrits, A. M. J., Pfister, L., and Savenije, H. H. G.: Spatial and temporal variability of canopy and forest floor interception in a beech forest, Hydrol. Process., 24, 3011-3025, doi:10.1002/hyp.7712, 2010.

Gravano, E., Bussotti, F., Grossoni, P., and Tani, C.: Morphoanatomical and functional modifications in beech leaves on the top ridge of the Apennines (Central Italy), Phyton Horn, 39, 4146, 1999.

Gupta, H., Kling, H., Yilmaz, K., and Martinez, G.: Decomposition of the mean squared error and NSE performance criteria: Implications for improving hydrological modelling, J. Hydrol., 377, 80-91, doi:10.1016/j.jhydrol.2009.08.003, 2009.

Hawdon, A., McJannet, D., and Wallace, J.: Calibration and correction procedures for cosmic-ray neutron soil moisture probes located across Australia, Water Resour. Res., 50, 5029-5043, doi:10.1002/2013WR015138, 2014.

Hendrick, L. D. and Edge, R. D.: Cosmic-ray neutrons near the Earth, Phys. Rev., 145, 1023-1025, 1966.

Howard, P. J. A. and Howard, D. M.: Use of organic carbon and loss-on-ignition to estimate soil organic matter in different soil types and horizons, Biol. Fertil. Soils, 9, 306-310, 1990.

Iwema, J., Rosolem, R., Baatz, R., Wagener, T., and Bogena, H. R.: Investigating temporal field sampling strategies for sitespecific calibration of three soil moisture-neutron intensity parameterisation methods, Hydrol. Earth Syst. Sci., 19, 3203-3216, doi:10.5194/hess-19-3203-2015, 2015.

Kling, H., Fuchs, M., and Paulin, M.: Runoff conditions in the upper Danube basin under an ensemble of climate change scenarios, J. Hydrol., 424-425, doi:10.1016/j.jhydrol.2012.01.011, 2012. 
Kodama, M., Kudo, S., and Kosuge, T.: Application of atmospheric neutrons to soil moisture measurement, Soil Sci., 140, 237-242, 1985.

Köhli, M., Schrön, M., Zreda, M., Schmidt, U., Dietrich, P., and Zacharias, S.: Footprint characteristics revised for field-scale soil moisture monitoring with cosmic-ray neutrons, Water Resour. Res., 51, 5772-5790, doi:10.1002/2015WR017169, 2015.

Lv, L., Franz, T., Robinson, D., and Jones, S.: Measured and modeled soil moisture compared with cosmic-ray neutron probe estimates in a mixed forest, Vadose Zone J., 13, doi:10.2136/vzj2014.06.0077, 2014.

Ochsner, T., Cosh, M., Cuenca, R., Dorigo, W., Draper, C., Hagimoto, Y., Kerr, Y., Njoku, E., Small, E., and Zreda, M.: State of the art in large-scale soil moisture monitoring, Soil Sci. Soc. Am. J., 77, 1888, doi:10.2136/sssaj2013.03.0093, 2013.

Rivera Villarreyes, C. A., Baroni, G., and Oswald, S. E.: Integral quantification of seasonal soil moisture changes in farmland by cosmic-ray neutrons, Hydrol. Earth Syst. Sci., 15, 3843-3859, doi:10.5194/hess-15-3843-2011, 2011.

Rosolem, R., Shuttleworth, W., Zreda, M., Franz, T., Zeng, X., and Kurc, S.: The effect of atmospheric water vapor on neutron count in the cosmic-ray soil moisture observing system, J. Hydrometeorol., 14, 1659-1671, doi:10.1175/JHM-D-12-0120.1, 2013.
Santa Regina, I., Tarazona, T., and Calvo, R.: Aboveground biomass in a beech forest and a Scots pine plantation in the Sierra de la Demanda area of northern Spain, Ann. Sci. Forest, 54, 261-269, doi:10.1051/forest:19970304, 1997.

Shuttleworth, J., Rosolem, R., Zreda, M., and Franz, T.: The COsmic-ray Soil Moisture Interaction Code (COSMIC) for use in data assimilation, Hydrol. Earth Syst. Sci., 17, 3205-3217, doi:10.5194/hess-17-3205-2013, 2013.

Western, A., Zhou, S.-L., Grayson, R., McMahon, T., Blöschl, G., and Wilson, D.: Spatial correlation of soil moisture in small catchments and its relationship to dominant spatial hydrological processes, J. Hydrol., 286, 113-134, doi:10.1016/j.jhydrol.2003.09.014, 2004.

Zreda, M., Desilets, D., Ferré, T., and Scott, R.: Measuring soil moisture content non-invasively at intermediate spatial scale using cosmic-ray neutrons, Geophys. Res. Lett., 35, L21402, doi:10.1029/2008GL035655, 2008.

Zreda, M., Shuttleworth, W., Zeng, X., Zweck, C., Desilets, D., Franz, T., and Rosolem, R.: COSMOS: the COsmic-ray Soil Moisture Observing System, Hydrol. Earth Syst. ScI., 16, 4079_ 4099, doi:10.5194/hess-16-4079-2012, 2012. 